1 Prefeitura Municipal de Caieiras - Caieiras (SP) Brasil.

2 Universidade Federal de São Paulo (Unifesp) - São Paulo (SP), Brasil.

leonardo.carnut@unifesp.br

3 Universidade de São Paulo (USP) - São Paulo (SP), Brasil.

4 Pontifícia Universidade Católica de São Paulo (PUC-SP) - São Paulo (SP) Brasil.

\section{Relação entre cumprimento das metas dos contratos de gestão e qualidade da atenção à saúde: uma revisão integrativa}

\author{
Relationship between goals achievement of management contracts \\ and quality of health care: an integrative review
}

Mariana Vieira de Melo', Leonardo Carnut², Áquilas Mendes ${ }^{\mathbf{3}, \mathbf{4}}$

DOI: $10.1590 / 0103-1104202113115$

RESUMO Trata-se de uma revisão sistemática integrativa da literatura realizada no portal da Biblioteca Virtual em Saúde com o objetivo de compreender se existe relação entre o cumprimento de metas e a qualidade da atenção à saúde. A estratégia de busca foi construída pelos polos: metas (fenômeno); contrato de gestão (população); e qualidade (contexto). A seleção foi feita através do protocolo Prisma por dois revisores, e a análise de dados realizada na modalidade temática, com foco na relação entre o cumprimento das metas e a qualidade. Dos 22 artigos incluídos na revisão, apenas 4 respondiam diretamente ao objeto desta pesquisa. 7 temas foram alvo de discussão nos artigos revisados: metodologia dos artigos; metas e seus cumprimentos nos contratos de gestão; tipos de contratualização; ideia de qualidade; aspectos do cumprimento do contrato de gestão; metas do contrato de gestão; e, por fim, a relação entre cumprimento das metas e qualidade. A maioria dos artigos revisados encontra-se no nível 4 de qualidade das evidências disponíveis. Com as evidências encontradas, foi possível concluir que as metas dos contratos de gestão não se relacionam com a qualidade da atenção à saúde e que faltam estudos que abordem o contexto brasileiro e do Sistema Único de Saúde (SUS).

PALAVRAS-CHAVE Contratos. Gestão em saúde. Parcerias Público-Privadas. Qualidade. Revisão.

\begin{abstract}
This study is a systematic integrative review was carried out on the Virtual Health Library portal to understand whether there is a relationship between the achievement of goals and the quality of health care. The search strategy was built by the poles: goals (phenomenon); management contract (population); and quality (context). The selection of publications was made through the Prisma protocol by two independent reviewers, and data analysis was carried out in the thematic mode, with focus on theme of the relationship between the achievement of goals and quality. Of the 22 articles included in the review, only 4 responded directly to the object of this research. 7 themes were discussed in the reviewed articles: methodology; goals and compliance with management contracts; types of contracting; quality idea; aspects of compliance with the management contract; management contract goals; and, finally, the relationship between achievement of goals and quality. Most of the articles reviewed refer to level 4 of quality evidence. With the evidence found, it was possible to conclude that the goals of management contracts are not related to the quality of health care and that there is a lack of studies that address the Brazilian context and the Unified Health System (SUS).
\end{abstract}

KEYWORDS Contracts. Health management. Public-Private Sector Partnerships. Quality. Review. 


\section{Introdução}

Baseado em experiências internacionais anteriores de reformas da administração pública, principalmente as ocorridas na Europa por volta da década de 1980, um movimento de reforma do Estado também ocorreu no Brasil nesse mesmo período com características neoliberais, especialmente ligado às privatizações 1 . Esse movimento internacional de 'reformas do Estado' estava em consonância com a dissolução do 'Estado Social Capitalista' europeu ${ }^{2}$ em virtude da queda da taxa de lucro que já vinha assolando o capitalismo mundial desde a década de $1970^{3}$.

É nesse cenário do capitalismo mundial nos países centrais que um dos objetivos iniciais dessa (contra)reforma administrativa foi reduzir a capacidade do Estado de salvaguardar os direitos relacionados ao trabalho e à vida social. No caso do Brasil, o direito à saúde como um direito social inscrito na constituição federal de 1988 foi um dos direitos atingidos por essa contrarreforma, esvaziando o ethos público dos serviços de saúde, tanto do ponto de vista da prestação quanto da gestão desses serviços.

Para os defensores da contrarreforma, pensando no campo da saúde pública, os argumentos residiam na maior flexibilidade gerencial com relação à compra de insumos e materiais e à contratação de recursos humanos, à gestão financeira dos recursos, e, além disso, à possibilidade de priorizar uma 'gestão baseada em resultados', visando à satisfação dos usuários e à qualidade dos serviços prestados'. No Brasil, a contrarreforma se daria em diversas modalidades, mas principalmente com a modificação da natureza jurídica dos serviços direcionados ao direito privado na relação jurídica entre gestão, trabalhadores e prestação dos serviços na saúde pública.

Impulsionada por Fernando Henrique Cardoso e idealizada por Luiz Carlos BresserPereira, nos anos de 1995, ocorre a contrarreforma administrativa do Aparelho do Estado. Esta, que tinha, entre vários outros objetivos, o da descentralização e transferência da execução de atividades desenvolvidas pelo Estado para iniciativa privada, incluindo a saúde $\mathbf{4}^{4}$ passou a ser o exemplo a ser seguido pelas esferas subnacionais nos anos subsequentes. A partir dessa contrarreforma, foram criadas, através das Leis no 9637/98 e n 9790/99, as Organizações Sociais (OS) e as Organizações da Sociedade Civil de Interesse Público (Oscip) na estrutura organizativa da administração pública ${ }^{1}$.

As OS caracterizam-se, formalmente, como entidades civis de interesse social e utilidade pública, de direito privado, sem fins lucrativos, que têm sua relação com o poder público pautada pelo contrato de gestão, que prevê como se dará a prestação do serviço cedido pelo Estado à entidade civil. Esse contrato de gestão detalha sobre multas em caso de descumprimento do acordo, resultados esperados, prestação de contas, processos de fiscalização, entre outros pontos da prestação do serviço ${ }^{\mathbf{1 , 4}}$. As OS foram criadas com a premissa de que exerceriam atividade pública descentralizada e ofereceriam maior autonomia e flexibilidade ao serviço público com vistas a aumentar sua eficiência e qualidade.

Segundo Barbosa e Elias 4 , a existência de metas nos contratos de gestão permite, por um lado, a melhor avaliação do desempenho das OS e indica os critérios de eficiência segundo os quais elas atuam, mas, por outro lado, gera uma cobrança excessiva e desvincula o alcance dos resultados projetados de um suposto impacto sobre os indicadores de saúde da população ${ }^{4}$. Essa cobrança excessiva gerada para o cumprimento das metas refere-se, principalmente, àquela exercida sobre os profissionais da saúde, pois modelos de gerenciamento mais flexíveis - como o proporcionado pelas OS seguem a lógica da economia de mercado, que regula as relações de trabalho minorando os cuidados necessários à saúde dos trabalhadores, para poder gerar aumento da carga e do ritmo de trabalho ${ }^{5}$. Essas organizações focam na melhoria do desempenho para atingir as metas e os resultados almejados, contudo, é 
importante ressaltar que o alcance dos resultados vem acompanhado de mecanismos de ganhos/perdas de incentivos dispostos nos contratos de gestão, ${ }^{6,7}$. Assim, em última instância, o desempenho fica resumido apenas a uma gradação de resultados, à produtividade $\mathrm{e}$ à quantidade de trabalho, deixando de funcionar como ferramenta gerencial para qualificar o serviço, não contribuindo para a tomada de decisão por não expressar a complexidade dos sistemas de saúde ${ }^{6,7}$.

Ao abordar o alcance de metas das organizações de serviços de saúde, é preciso pensar em formas de avaliação do desempenho e da qualidade dos serviços prestados ${ }^{8}$. Um dos referenciais teóricos que tem sido mais utilizado para a avaliação da qualidade em saúde é o proposto por Donabedian, que aborda as seguintes dimensões: estrutura, processo e resultados 9,10 . No que se refere à 'estrutura', tem-se que ela poderia possibilitar o desenvolvimento de um adequado processo de cuidados com resultados favoráveis; já o 'processo' se baseia na expressão da aplicação do conhecimento existente e de tecnologias disponíveis no cuidado que podem resultar em efeitos favoráveis na saúde; e os 'resultados' são o que se refere à promoção, à proteção e à recuperação da saúde, e também à satisfação do paciente decorrente dos cuidados prestados 9,10 .

Para Donabedian, a qualidade em saúde seria composta por atributos como: 'cobertura, acessibilidade e equidade', que se relacionam a: disponibilidade e distribuição social dos recursos de saúde; 'eficácia e efetividade', que seriam os efeitos das ações e práticas implementadas; 'eficiência', relacionada aos custos das ações em saúde; 'técnico-científico', relacionado à adequação das ações ao conhecimento e às tecnologias disponíveis; e 'aceitabilidade', ligada à percepção do usuário e ao conceito de satisfação, ${ }^{9,10}$. A avaliação desses atributos pode auxiliar na estimativa do impacto esperado de determinadas práticas com relação aos problemas de saúde a elas vulneráveis ${ }^{\mathbf{1 0}}$. Conhecer os conceitos de Donabedian e aplicá-los à análise dos contratos de gestão e do serviço ofertado pelas OS pode demonstrar alguns dos impactos desse modelo de gestão na assistência à saúde.

Numa busca inicial da literatura, é possível notar a existência de estudos que descrevem características das OS e falam sobre a contrarreforma do Estado. Outras pesquisas específicas abordam a qualidade em serviços de saúde e uso de ferramentas para melhoria gerencial e para sua mensuração, além dos estudos que comparam o desempenho de serviços administrados por OS e pela administração direta do Estado. No entanto, pouco se discute sobre a relação entre os contratos de gestão, seu cumprimento e o real aumento da qualidade na saúde. Diante desse contexto, o objetivo deste trabalho é revisar se existe relação entre o cumprimento das metas dos contratos de gestão e a qualidade da atenção à saúde.

\section{Metodologia}

Trata-se de uma revisão sistemática integrativa da literatura, escolhida como método por ser realizada de forma sistemática e rigorosa através da síntese de achados provenientes de pesquisas desenvolvidas" ${ }^{11}$.

\section{Fonte dos dados e estratégia de busca}

A partir do questionamento 'o que a literatura científica apresenta sobre o cumprimento das metas quantitativas dos contratos de gestão e sua relação com a qualidade da atenção à saúde?', foram delimitados itens-chave derivados dos descritores formalmente catalogados através da plataforma Descritores em Ciências da Saúde (http://decs.bvs.br/).

Os itens-chave e os descritores foram definidos conforme o quadro 1 . 
Quadro 1. Itens-chave da pergunta de pesquisa, descritores derivados dos itens-chave e polo da estratégia de busca que cada um dos itens representa. 2020

\begin{tabular}{|c|c|c|}
\hline Item-chave & Descritores & Polo \\
\hline Metas & $\begin{array}{l}\text { Objetivos; Objetivos Organizacionais; Benchmarking; Desempenho profissional; Ava- } \\
\text { liação em Saúde; Avaliação de Desempenho Profissional; Pesquisa sobre Serviços de } \\
\text { Saúde; Avaliação de Processos e Resultados em Cuidados de Saúde; Avaliação de } \\
\text { Programas e Projetos de Saúde; Avaliação de Processos em Cuidados de Saúde; Ava- } \\
\text { liação de Resultados em Cuidados de Saúde; Mecanismos de Avaliação da Assistência } \\
\text { à Saúde; Avaliação de Recursos Humanos em Saúde; Indicadores de Qualidade em } \\
\text { Assistência à Saúde; Indicadores de Serviços; Indicadores Básicos de Saúde; Indicadores } \\
\text { de Gestão; Eficiência Organizacional; Análise Custo-Eficiência; Medidas de Resultados } \\
\text { Relatados pelo Paciente. }\end{array}$ & Fenômeno \\
\hline $\begin{array}{l}\text { Contrato de } \\
\text { gestão }\end{array}$ & $\begin{array}{l}\text { Administração de Serviços de Saúde; Gerenciamento da Prática Profissional; Gestão } \\
\text { em Saúde; Governança Clínica; Gestão de Recursos da Equipe de Assistência à Saúde; } \\
\text { Gestão da Saúde da População; Administração em Saúde Pública; Políticas, Planejamen- } \\
\text { to e Administração em Saúde; Administração em Saúde; Administração de Instituições } \\
\text { de Saúde; Economia e Organizações de Saúde; Organizações de Planejamento em Saú- } \\
\text { de; Organizações sem Fins Lucrativos; Organizações em Saúde; Privatização; Parcerias } \\
\text { Público-Privadas; Modernização do Setor Público; Contratos; Serviços Contratados. }\end{array}$ & População \\
\hline Qualidade & $\begin{array}{l}\text { Garantia da Qualidade dos Cuidados de Saúde; Controle de Qualidade; Qualidade da } \\
\text { Assistência à Saúde; Qualidade, Acesso e Avaliação da Assistência à Saúde; Gestão da } \\
\text { Qualidade Total; Gestão da Qualidade; Melhoria de Qualidade; Avaliação do Impacto na } \\
\text { Saúde. }\end{array}$ & Contexto \\
\hline
\end{tabular}

Fonte: Elaboração própria.

A etapa seguinte foi realizar testes exploratórios com os descritores para verificar sua utilização pela comunidade científica, primeiro avaliando cada descritor individualizado e depois combinando todos os descritores do item-chave 'metas' com todos os demais descritores dos outros itens-chave utilizando o operador booleano 'AND'.

Após a fase de testes, construiu-se a sintaxe de pesquisa de maneira ampla, sistematizada e reprodutível. Dentro de um mesmo item-chave foi utilizado o operador booleano 'OR' entre os descritores, com o objetivo de tornar a busca abrangente; e, na combinação entre os itens-chave, o operador booleano 'AND' para restringir os resultados e contemplar os polos população, fenômeno e contexto determinados pela pergunta de pesquisa. Realizou-se a busca na Biblioteca Virtual em Saúde (BVS) (http://bvsalud.org/), escolhida por integrar diferentes bases de dados bibliográficos de informação em saúde.
A composição da sintaxe final foi feita com uso do operador booleano 'AND' conectando os três polos e chegando a 1.041 estudos identificados para posterior análise, ficando da seguinte forma: (mh:(mh:("objetivos" OR "objetivos organizacionais" OR "benchmarking" OR “desempenho profissional” OR "avaliacao em saude" OR "avaliacao de desempenho profissional" OR "pesquisa sobre servicos de saude" OR "avaliacao de processos e resultados em cuidados de saude" OR "avaliacao de programas e projetos de saude" OR "avaliacao de processos em cuidados de saude" OR "avaliacao de resultados em cuidados de saude" OR "mecanismos de avaliacao da assistencia a saude" OR "avaliacao de recursos humanos em saude" OR "indicadores de qualidade em assistencia a saude" OR "indicadores de servicos" OR "indicadores basicos de saude" OR "indicadores de gestao" OR "eficiencia organizacional" OR "analise custo-eficiencia” OR "medidas de resultados relatados pelo 
paciente”))) AND (mh:(mh:(“administracao de servicos de saude" OR "gerenciamento da pratica profissional" "gestao em saude" OR "governanca clinica" OR "gestao de recursos da equipe de assistencia a saude" OR "gestao da saude da populacao" OR "administracao em saude publica" OR "politicas, planejamento e administracao em saude" OR "administracao em saude" OR "administracao de instituicoes de saude" OR "economia e organizacoes de saude" OR "organizacoes de planejamento em saude" OR "organizacoes sem fins lucrativos" OR "organizacoes em saude" OR "privatizacao" OR "parcerias publico-privadas" OR "modernizacao do setor publico" OR "contratos" OR "servicos contratados"))) AND (mh:(mh:("garantia da qualidade dos cuidados de saude" OR "controle de qualidade" OR "qualidade da assistencia a saude" OR "qualidade, acesso e avaliacao da assistencia a saude" OR "gestao da qualidade total" OR "gestao da qualidade" OR "melhoria de qualidade" OR "avaliacao do impacto na saude"))).

Com a finalização da sintaxe, seguiu-se o processo de seleção dos estudos identificados acompanhando o fluxograma Prisma, apresentado na figura 1:

Figura 1. Fluxograma Prisma sobre o processo de seleção dos artigos incluídos na revisão. 2021

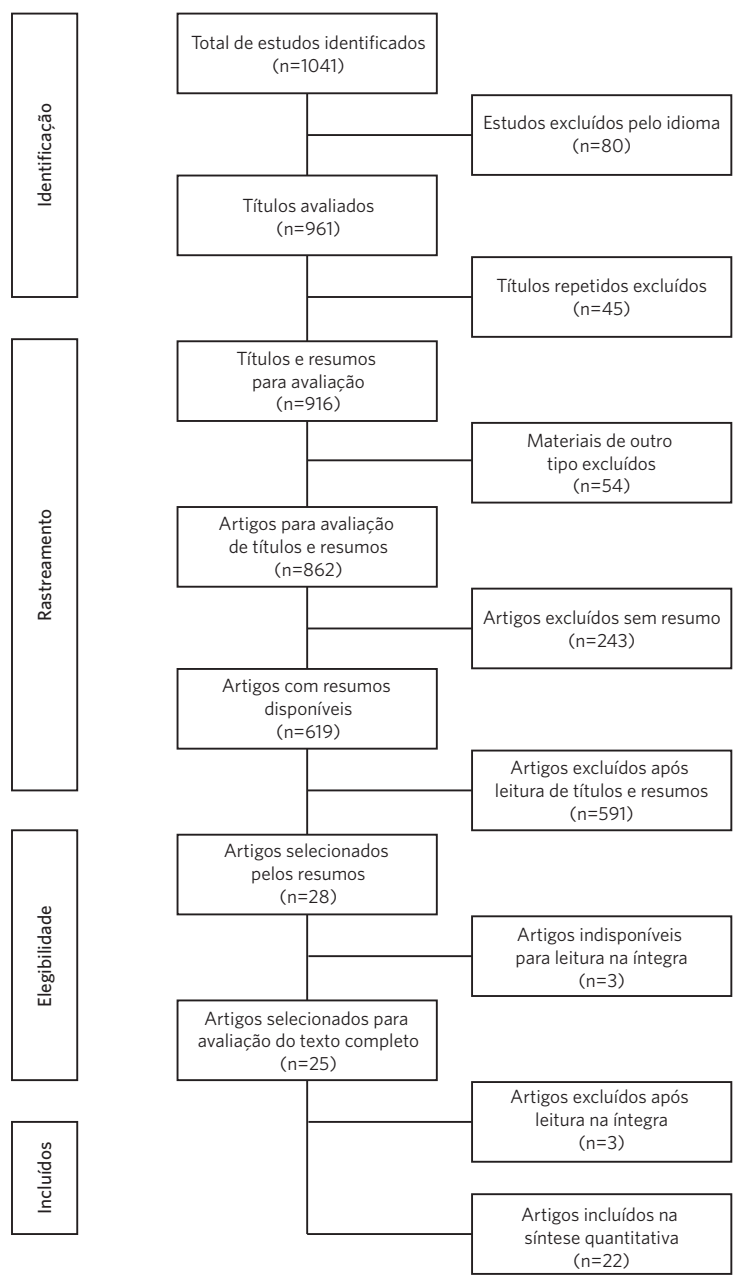


Na primeira etapa do fluxograma, relacionada à identificação dos estudos, foram excluídos os títulos escritos em outras línguas que não fossem a inglesa, portuguesa ou a espanhola, compondo um total de 80 títulos, divididos nos seguintes idiomas: 11 em chinês, 11 em árabe, 15 em russo, 18 em francês, 3 em italiano, 1 em polonês e 21 em alemão. Por conseguinte, foram descartados 45 títulos duplicados e passou-se para a fase de rastreamento com a análise do tipo de estudos disponíveis de 916 títulos. Nessa etapa foram excluídos outros 54 títulos que não se apresentavam no formato de artigo, sendo eles: 13 teses, 20 monografias, 5 livros, 3 dissertações e 13 relatórios de congressos e eventos.

Os próximos passos foram a exclusão de 243 artigos que não apresentavam resumo e a leitura de títulos e resumos disponíveis. Após a leitura, 591 títulos foram descartados por não se relacionarem com o questionamento que norteia esta pesquisa. Esses artigos tratavam de temas como gestão da qualidade total, uso de diversas ferramentas para mensuração da qualidade, sobre o desempenho de programas e serviços de saúde específicos, relação custo-benefício em diferentes contextos, pagamento por performance médica, descrição e análise dos sistemas de saúde de diferentes localidades, gerenciamento de projetos e de processos de trabalho na área da saúde, sobre governança clínica e características do gestores em saúde, sobre acreditação e auditoria de serviços de saúde, uso de indicadores para análise da assistência à saúde, desenvolvimento de habilidades gerenciais e habilidades dos profissionais e outros assuntos que não tratavam da relação entre cumprimento de metas dos contratos de gestão e qualidade da atenção à saúde. Essa fase resultou em 28 artigos para análise.

$\mathrm{Na}$ fase de elegibilidade, 3 artigos foram excluídos por não estarem disponíveis para leitura na íntegra, e restaram 25 artigos para avaliação do texto completo. Após leitura na íntegra, outros 3 artigos foram excluídos por não se relacionarem com o objeto de pesquisa, restando 22 artigos para análise.

\section{Análise de dados}

O processo de análise dos dados dos 22 artigos incluídos seguiu a realização do método da revisão integrativa, incluindo as etapas de extração, visualização, comparação e sintetização das conclusões dos dados. A extração de dados foi concluída de forma independente por 2 revisores (M.V.M. e L.C). O formulário de extração de dados foi elaborado com base na questão de pesquisa que norteou esta revisão.

Os dados extraídos dos artigos incluem autor (ano de publicação), país, metodologia utilizada, objetivo, principais resultados e os elementos que relacionam o artigo com a pergunta de pesquisa: metas e seus cumprimentos, tipo de contrato de gestão (contratualização) e a ideia de qualidade. Para completar essas informações, identificou-se, também, o nível de atenção à saúde em que a contratualização acontecia (quando o artigo mencionava). A integração dos dados foi operacionalizada pelo método da análise temática, contribuindo para que a tipologia dos manuscritos permitisse uma integração mais refinada dos dados. Assim, organizaram-se os temas para cada elemento a seguir: metodologia (para discutir a qualidade e a força das evidências), a relação entre objetivos e resultados encontrados, os elementos específicos da pergunta de pesquisa (as metas, o cumprimento das metas, o tipo de contratualização e a idea de qualidade da atenção). Por fim, os aspectos mais focados nas características do uso das metas e seu cumprimento nos contratos - como presença de um estudo de linha-base, multas e punições, bonificação, tipos de metas (quantitativas ou qualitativas) e se o cumprimento da meta impacta a qualidade da atenção - foram analisados.

\section{Resultados}

Os artigos são, em sua maioria, estudos de caso e abrangem diversos países - existindo representantes de todos os continentes -, com características culturais, socioeconômicas, 
epidemiológicas e de sistemas de saúde diferentes entre si. Também foi diverso o nível de atenção à saúde abordado nos artigos, sendo o mais citado a atenção primária. Essa diversidade sugere o quanto o fenômeno de contratualização é comum e tem ganhado espaço dentro de diferentes sistemas de saúde.

Para a maioria dos estudos, a qualidade é reduzida à ideia de cumprir metas e atingir determinados indicadores. Apenas um artigo ${ }^{\mathbf{1 2}}$ aborda a avaliação da qualidade seguindo o referencial teórico proposto por Donabedian, e outro artigo ${ }^{13}$ menciona uma definição utilizada para qualidade dos cuidados em saúde, além de citar a Teoria das falhas do contrato ao comparar organizações com e sem fins lucrativos. Um dos artigos ${ }^{\mathbf{1 4}}$ especifica o que seria um sistema de saúde de qualidade, trazendo a importância do acesso, eficácia e eficiência, conceitos que também são citados pelo artigo de Ashton et al. ${ }^{15}$.

Para melhor apreciação dos resultados, os artigos foram classificados em três grupos distintos, conforme o quadro 2 . O primeiro grupo compreende os estudos que tangenciam o objeto desta pesquisa ${ }^{12,13,16-19}$, ou seja, discorrem sobre contratualizações e relação entre público e privado, porém, não tratam das metas estabelecidas nesse tipo de contrato e não as relacionam com avaliações de qualidade em saúde. Nesse grupo, os artigos tratam, principalmente, da análise do papel das organizações sem fins lucrativos e da comparação entre instituições com fins lucrativos, da definição do modelo de parceria público-privada e da percepção divergente que diferentes atores da saúde (profissionais públicos e privados, gestores e acadêmicos) têm sobre esse modelo, comparação da qualidade entre serviços ofertados pelos entes público e privado, avaliação de critérios de seleção de organizações não governamentais para escolha da parceria mais eficiente, riscos e benefícios e casos de sucessos e fracassos da implementação de Parcerias Público-Privadas (PPP).

O segundo grupo abrange os artigos ${ }^{\mathbf{1 4}, 15,20-29}$, que respondem parcialmente ao questionamento desta revisão, visto que citam as metas ou citam seus cumprimentos no contrato de gestão, mas não aprofundam a maneira como são mensurados ou não possuem metas claras estabelecidas. Outro ponto a ser mencionado é que esse grupo contém artigos que não abordam a qualidade dos serviços de saúde estudados ou fazem a mensura sem nenhum tipo de relação com as metas referidas.

O terceiro grupo contém os artigos ${ }^{30-33}$, que respondem diretamente ao objeto desta pesquisa. A partir deles, pode-se estabelecer a relação entre cumprimento das metas quantitativas dos contratos de gestão e a qualidade da atenção à saúde. Dos quatro estudos apresentados, dois deles ${ }^{31,33}$ não estabelecem nenhuma relação de impacto entre metas e qualidade, e outros dois não $0^{\mathbf{3 0}, 32}$ estabelecem relação porque a forma de mensurar a qualidade e os indicadores utilizados diverge daquela estabelecida como meta nos contratos. 
Quadro 2. Síntese dos artigos incluídos segundo autor/ano, país, método, objetivo, principais resultados, metas e seus cumprimentos, tipos de contratualização e ideia de qualidade. 2020

\begin{tabular}{|c|c|c|c|c|c|c|}
\hline \multirow[b]{2}{*}{ Objetivo } & \multirow[b]{2}{*}{ Principais Resultados } & \multicolumn{2}{|c|}{ Metas e seus Cumprimentos } & \multirow{2}{*}{$\begin{array}{l}\text { Tipo de } \\
\text { Contratualização }\end{array}$} & \multirow[b]{2}{*}{ Ideia de Qualidade } & \multirow{2}{*}{$\begin{array}{l}\text { Nível de } \\
\text { atenção }\end{array}$} \\
\hline & & Metas & Cumprimentos & & & \\
\hline \multicolumn{7}{|c|}{ Grupo A - Estudos que tangenciam o objeto de pesquisa } \\
\hline \multicolumn{7}{|c|}{ Top e Sungur, 201816. Turquia - Estudo de caso - qualitativo } \\
\hline $\begin{array}{l}\text { Definir o modelo de PPP, } \\
\text { identificando as visões } \\
\text { dos stakeholders e asso- } \\
\text { ciando com as políticas } \\
\text { de saúde. Avaliar um dos } \\
\text { projetos (em hospitais) } \\
\text { para determinar as van- } \\
\text { tagens e desvantagem do } \\
\text { modelo. }\end{array}$ & $\begin{array}{l}\text { Funcionários de ONGs e } \\
\text { servidores públicos tendem } \\
\text { a ter uma visão negativa das } \\
\text { PPP, enquanto acadêmicos, } \\
\text { funcionários do setor privado e } \\
\text { alto escalão público têm uma } \\
\text { visão positiva. A maioria dos } \\
\text { entrevistados acreditava que o } \\
\text { modelo PPP era adequado para } \\
\text { os 'integrated health-campus' } \\
\text { na Turquia. }\end{array}$ & Não contempla. & Não contempla. & $\begin{array}{l}\text { Build-rent-transfer (con- } \\
\text { cessão) }\end{array}$ & Não contempla. & Terciária \\
\hline
\end{tabular}

\section{Almeida, 201717. Portugal - Revisão sistemática + estudo de caso}

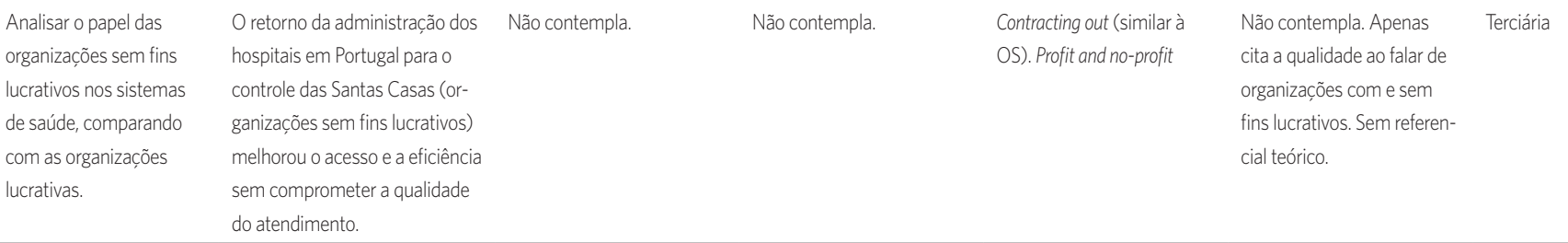

\section{Souza e Scatena, 2013'2. Brasil - Estudo multicaso descritivo, com abordagem quantitativa (parte de doutorado)}

\begin{tabular}{|c|c|c|c|c|c|c|}
\hline Avaliar a qualidade da & Nesta avaliação, utilizando o & Não contempla. & Não contempla. & OS & Relacionado ao Programa & Terciária \\
\hline assistência hospitalar & roteiro de padrões de conformi- & & & & Nacional de Avaliação dos & \\
\hline prestada por dez hos- & dade do PNASS, destacaram-se & & & & Serviços de Saúde - PNASS & \\
\hline pitais que compõem o & os hospitais públicos geridos & & & & (baseado no modelo de & \\
\hline mix público-privado do & por OSS e os filantrópicos. & & & & estrutura, processos e & \\
\hline SUS no estado de Mato & Ressalta-se que nenhum dos & & & & resultados) & \\
\hline \multirow[t]{7}{*}{ Grosso. } & hospitais privados estudados & & & & & \\
\hline & apareceu entre aqueles com & & & & & \\
\hline & maiores pontuações, pelo & & & & & \\
\hline & contrário, geralmente eles & & & & & \\
\hline & estavam representados entre & & & & & \\
\hline & os que obtiveram menores & & & & & \\
\hline & pontuações. & & & & & \\
\hline \multicolumn{7}{|c|}{ Heard et al., 201118. Índia - Estudo de caso } \\
\hline \multirow{10}{*}{$\begin{array}{l}\text { Avaliar o processo de } \\
\text { contratação avaliando } \\
\text { a seleção das ONGs e } \\
\text { o seus desempenhos. } \\
\text { Determinar se poderiam } \\
\text { ser usados critérios de } \\
\text { seleção mais eficientes. }\end{array}$} & A experiência no treinamento & Não contempla. Cita como & Não contempla. & ONGS. Contracting out & Não contempla. & APS \\
\hline & dos profissionais e a qualidade & as ONGS seriam avaliadas: & & (similar à OS) & & \\
\hline & da proposta do projeto da ONG & de acordo com a gestão de & & & & \\
\hline & foram preditores significativos & suas unidades e o alcance & & & & \\
\hline & do seu desempenho, já as me- & de indicadores como cuida- & & & & \\
\hline & didas de estabilidade financeira & dos pré-natais, imunização & & & & \\
\hline & da ONG não serviam como & e outros. & & & & \\
\hline & preditores. Interessante que & & & & & \\
\hline & o indicador de experiência da & & & & & \\
\hline & ONG não foi um bom preditivo. & & & & & \\
\hline
\end{tabular}


Quadro 2. (cont.)

\begin{tabular}{|c|c|c|c|c|c|c|}
\hline \multirow[b]{2}{*}{ Objetivo } & \multirow[b]{2}{*}{ Principais Resultados } & \multicolumn{2}{|c|}{ Metas e seus Cumprimentos } & \multirow{2}{*}{$\begin{array}{l}\text { Tipo de } \\
\text { Contratualização }\end{array}$} & \multirow[b]{2}{*}{ Ideia de Qualidade } & \multirow{2}{*}{$\begin{array}{l}\text { Nível de } \\
\text { atenção }\end{array}$} \\
\hline & & Metas & Cumprimentos & & & \\
\hline \multicolumn{7}{|c|}{ Sekhri et al., 20119. EUA - Ensaio descritivo } \\
\hline $\begin{array}{l}\text { Descrever o modelo } \\
\text { integrado de parceria } \\
\text { público-privada detalha- } \\
\text { damente, evidenciando } \\
\text { os potenciais riscos e be- } \\
\text { nefícios. Descrever como } \\
\text { esse modelo difere de } \\
\text { outros tipos de parcerias, } \\
\text { dar exemplos de par- } \\
\text { cerias em vários países } \\
\text { e examinar sucessos e } \\
\text { fracassos. }\end{array}$ & $\begin{array}{l}\text { Não apresenta. Sem resultados } \\
\text { por não se tratar de um estudo } \\
\text { empírico. }\end{array}$ & $\begin{array}{l}\text { Não contempla. Apenas } \\
\text { cita a existência de metas } \\
\text { neste tipo de parceria. }\end{array}$ & $\begin{array}{l}\text { Não contempla. Apenas } \\
\text { cita que o parceiro privado é } \\
\text { pago com base nos resulta- } \\
\text { dos de seu desempenho e } \\
\text { fica responsável por atender } \\
\text { aos padrões de qualidade. }\end{array}$ & PPP & $\begin{array}{l}\text { Não contempla.Não cita } \\
\text { nenhum referencial teórico } \\
\text { nem qual seria sua ideia de } \\
\text { qualidade. }\end{array}$ & $\begin{array}{l}\text { Não es- } \\
\text { pecifica }\end{array}$ \\
\hline \multicolumn{7}{|c|}{ Haldiman e Tzeng, 2010'13. EUA - Estudo transversal } \\
\hline $\begin{array}{l}\text { Investigar as diferenças } \\
\text { das médias das medidas } \\
\text { de qualidade entre as } \\
\text { agências de cuidado } \\
\text { domiciliar com e sem fins } \\
\text { lucrativos em Michigan. }\end{array}$ & $\begin{array}{l}\text { As organizações com fins } \\
\text { lucrativos tiveram melhor } \\
\text { desempenho. }\end{array}$ & Não contempla. & Não contempla. & Não contempla. & $\begin{array}{l}\text { Define qualidade dos } \\
\text { cuidados em saúde como } \\
\text { "um equilibrio ideal entre as } \\
\text { possibilidades realizadas e } \\
\text { uma estrutura de normas e } \\
\text { valores." 'The contract failu- } \\
\text { re theory' - teoria econômi- } \\
\text { ca que explica a diferença } \\
\text { entre organizações com e } \\
\text { sem fins lucrativos. }\end{array}$ & $\begin{array}{l}\text { Atenção } \\
\text { domiciliar }\end{array}$ \\
\hline
\end{tabular}

Grupo B - Estudos que respondem parcialmente ao objeto de pesquisa

\section{Field et al., 201820. Papua-Nova Guiné - Estudo de caso}

\begin{tabular}{|c|c|c|c|c|c|c|}
\hline $\begin{array}{l}\text { Avaliar quantitativamen- } \\
\text { te e qualitativamente as } \\
\text { mudanças na prestação } \\
\text { dos serviços de saúde } \\
\text { após implementação de } \\
\text { parceria público-privada. }\end{array}$ & $\begin{array}{l}\text { Melhora dos indicadores dos } \\
\text { serviços de saúde em com- } \\
\text { paração ao período anterior } \\
\text { à implementação da parceria } \\
\text { público-privada. }\end{array}$ & $\begin{array}{l}\text { Aumento dos indicadores: } \\
\text { taxa de pacientes am- } \\
\text { bulatoriais, imunização, } \\
\text { planejamento familiar, } \\
\text { atendimento pré-natal e } \\
\text { partos supervisionados. } \\
\text { Não especifica o quanto de } \\
\text { aumento a ser alcançado. } \\
\text { Melhora dos equipamen- } \\
\text { tos e infraestruturas das } \\
\text { unidades de saúde. }\end{array}$ & Não contempla. & $\begin{array}{l}\text { Similar ao contracting-out e } \\
\text { à parceria público privada } \\
\text { (PPP), mas difere por ser } \\
\text { contratada por uma ONG } \\
\text { em nome da comunidade } \\
\text { que financia o programa. }\end{array}$ & $\begin{array}{l}\text { Realizou apenas avaliação } \\
\text { qualitativa da percepção } \\
\text { dos profissionais de } \\
\text { saúde através de entrevista } \\
\text { semiestruturada, que incluía } \\
\text { tópicos sobre as mudanças } \\
\text { percebidas após a PPP, } \\
\text { barreiras e facilitadores para } \\
\text { fornecer serviços de saúde } \\
\text { de qualidade. }\end{array}$ & APS \\
\hline \multicolumn{7}{|c|}{ Gardner et al., 2016²1. Austrália - Revisão sistemática } \\
\hline $\begin{array}{l}\text { Avaliar as evidências do } \\
\text { impacto do comissiona- } \\
\text { mento nos serviços de } \\
\text { saúde, qualidade, resul- } \\
\text { tados e valor financeiro } \\
\text { considerando os achados } \\
\text { no contexto australiano. }\end{array}$ & $\begin{array}{l}\text { Existem poucos estudos sobre } \\
\text { o monitoramento e avaliação } \\
\text { do desempenho dos contra- } \\
\text { tos. Há poucas evidências da } \\
\text { eficácia do comissionamento } \\
\text { e os impactos são contexto- } \\
\text {-dependentes. }\end{array}$ & Não contempla. & Não contempla. & Comissionamento & $\begin{array}{l}\text { Recomenda ênfase em } \\
\text { mensurar resultados } \\
\text { clínicos e experiência do } \\
\text { paciente para resultar em } \\
\text { melhora da qualidade do } \\
\text { atendimento. }\end{array}$ & $\begin{array}{l}\text { Todos os } \\
\text { níveis }\end{array}$ \\
\hline
\end{tabular}


Quadro 2. (cont.)

\begin{tabular}{|c|c|c|c|c|c|c|}
\hline \multirow[b]{2}{*}{ Objetivo } & \multirow[b]{2}{*}{ Principais Resultados } & \multicolumn{2}{|c|}{ Metas e seus Cumprimentos } & \multirow{2}{*}{$\begin{array}{l}\text { Tipo de } \\
\text { Contratualização }\end{array}$} & \multirow[b]{2}{*}{ Ideia de Qualidade } & \multirow{2}{*}{$\begin{array}{l}\text { Nível de } \\
\text { atenção }\end{array}$} \\
\hline & & Metas & Cumprimentos & & & \\
\hline \multicolumn{7}{|c|}{ O'Brien et al., 2016 ${ }^{14}$. Austrália - Estudo de caso } \\
\hline $\begin{array}{l}\text { Descrever o modelo } \\
\text { de comissionamento } \\
\text { implementado no Sul da } \\
\text { Austrália. }\end{array}$ & $\begin{array}{l}\text { Melhora da prática clínica, } \\
\text { redução do número de interna- } \\
\text { ções hospitalares e melhora do } \\
\text { cuidado em todo o sistema de } \\
\text { saúde obtidas com o comissio- } \\
\text { namento. }\end{array}$ & $\begin{array}{l}\text { Não contempla.Enfatiza a } \\
\text { importância de se estabe- } \\
\text { lecerem metas e avaliar } \\
\text { resultados de forma geral. } \\
\text { Também cita que as metas } \\
\text { variam pela especificidade } \\
\text { de cada oferta de serviço de } \\
\text { saúde (exemplo de centros } \\
\text { de tratamento de câncer). }\end{array}$ & $\begin{array}{l}\text { Fala sobre desenvolver } \\
\text { um sistema de dados para } \\
\text { monitorar os resultados e } \\
\text { pontua que a estrutura de } \\
\text { gestão de desempenho } \\
\text { precisa evoluir. Contratos } \\
\text { ainda precisam melhorar } \\
\text { para garantir maior res- } \\
\text { ponsabilidade quando o } \\
\text { comissionamento tem um } \\
\text { desempenho inferior às } \\
\text { metas estabelecidas. }\end{array}$ & Comissionamento & $\begin{array}{l}\text { Princípios de um sistema } \\
\text { de saúde de qualidade: cen- } \\
\text { trado no paciente, seguro, } \\
\text { eficaz, acessível, eficiente, } \\
\text { equitativo. }\end{array}$ & $\begin{array}{l}\text { Todos os } \\
\text { níveis }\end{array}$ \\
\hline
\end{tabular}

\footnotetext{
Responder por quais razões o processo de contratação de PPP em saúde tem apresentado dificuldades em sua implantação e contratação.

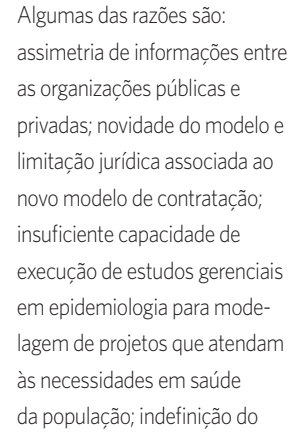

Barbosa e Malik, 201522. Brasil - Estudo qualitativo baseado na tríade tese-antítese-síntese para construção da análise crítica

PPP

Não contempla.

Todos os existência dos contratos de nem todos os contratos gestão e algumas de suas possuíam indicadores características, como a de desempenho a serem pactuação de metas. monitorados.

níveis de

atenção.

\section{Lee e McKee, 2015²3. Costa Rica - Estudo de caso}

Avaliar se a descentralização afetou a eficiência clínica e a saúde da população. Comparar regiões que permaneceram centralizadas em relação às descentralizadas.
Redução do custo nas áreas descentralizadas sem afetar os indicadores de saúde da população de forma negativa (também não houve aumento significativo quando comparado com as áreas centralizadas), portanto, melhora apenas na eficiência.

\author{
Não contempla.Não deixa \\ claro quais valores deve- \\ riam ser atingidos. \\ Incentivo de $10 \%$ do \\ orçamento da clínica ou \\ hospital com base em \\ medidas de qualidade \\ de cuidados de saúde e \\ utilização de recursos, \\ incluindo taxas de infecções \\ intra-hospitalares, taxas de \\ readmissão, duração média \\ das listas de espera, taxa de \\ absenteísmo de profissio- \\ nais de saúde, tempo médio \\ de internação.
}

\begin{tabular}{|c|c|c|c|c|c|c|}
\hline \multicolumn{7}{|c|}{ Gridley et al., 2012²4. Reino Unido - Aborda dois estudos qualitativos } \\
\hline $\begin{array}{l}\text { Explorar as principais } \\
\text { premissas que sustentam } \\
\text { o desenvolvimento con- } \\
\text { tínuo do gerenciamento } \\
\text { por GP (General Practioner } \\
\text { - Médico de Família) em } \\
\text { serviços de saúde. }\end{array}$ & $\begin{array}{l}\text { Sugere que nem sempre os } \\
\text { GPs são os coordenadores do } \\
\text { cuidado em todas as questões } \\
\text { de saúde e que o gerenciamen- } \\
\text { to por esses grupos não estará } \\
\text { sujeito à gestão de desempe- } \\
\text { nho, o que levanta a questão } \\
\text { de como padrões de qualidade } \\
\text { serão atendidos. }\end{array}$ & $\begin{array}{l}\text { Não contempla.Ainda não } \\
\text { estabelecidas, mas cita algo } \\
\text { sobre reduzir dias de inter- } \\
\text { nação em } 5 \% \text { em } 3 \text { anos; } \\
\text { promover saúde infantil } \\
\text { próximo ao domicílio. }\end{array}$ & $\begin{array}{l}\text { Não contempla.Cita que } \\
\text { incentivos financeiros } \\
\text { podem ajudar a alcançar } \\
\text { resultados, mas quais se- } \\
\text { riam os resultados e como } \\
\text { o incentivo seria ofertado } \\
\text { ainda não foi estabelecido. }\end{array}$ & $\begin{array}{l}\text { CCG - Clinical Commissio- } \\
\text { ning Groups }\end{array}$ & $\begin{array}{l}\text { Baseada nos padrões } \\
\text { do National Institute for } \\
\text { Health and Clinical Excel- } \\
\text { lence (Nice), mas ainda não } \\
\text { implementada. }\end{array}$ & $\begin{array}{l}\text { Secun- } \\
\text { dária e } \\
\text { terciária }\end{array}$ \\
\hline
\end{tabular}


Quadro 2. (cont.)

\begin{tabular}{|c|c|c|c|c|c|c|}
\hline \multirow[b]{2}{*}{ Objetivo } & \multirow[b]{2}{*}{ Principais Resultados } & \multicolumn{2}{|c|}{ Metas e seus Cumprimentos } & \multirow{2}{*}{$\begin{array}{l}\text { Tipo de } \\
\text { Contratualização }\end{array}$} & \multirow[b]{2}{*}{ Ideia de Qualidade } & \multirow{2}{*}{$\begin{array}{l}\text { Nível de } \\
\text { atenção }\end{array}$} \\
\hline & & Metas & Cumprimentos & & & \\
\hline \multicolumn{7}{|c|}{ Ameli e Newbrander, 200825. Afeganistão - Estudo transversal } \\
\hline $\begin{array}{l}\text { Pesquisar os efeitos das } \\
\text { mudanças na utilização e } \\
\text { na qualidade dos serviços } \\
\text { de saúde com relação } \\
\text { aos custos do BPHS } \\
\text { Basic Package of Health } \\
\text { Services. }\end{array}$ & $\begin{array}{l}\text { O acesso aos serviços de saúde } \\
\text { pode ser estendido por meio } \\
\text { de mecanismos de contra- } \\
\text { tação em um estado de pós- } \\
\text {-conflito, mesmo na presença } \\
\text { de problemas de segurança. As } \\
\text { características dos serviços de } \\
\text { saúde, sua qualidade, distância } \\
\text { geográfica e situação de segu- } \\
\text { rança não explicam as variações } \\
\text { no custo per capita. Usar esses } \\
\text { parâmetros para um plane- } \\
\text { jamento não implicaria uma } \\
\text { melhor alocação de recursos. }\end{array}$ & $\begin{array}{l}\text { Não cita claramente. Fala } \\
\text { apenas que segurança e } \\
\text { isolamento foram conside- } \\
\text { rados fatores importantes } \\
\text { do custo do contrato por } \\
\text { acreditarem que fosse mais } \\
\text { caro fornecer serviços de } \\
\text { saúde em áreas remotas e } \\
\text { menos seguras. }\end{array}$ & Não contempla. & $\begin{array}{l}\text { Contracting out (similar à } \\
\text { OS) com ONGs. Financiado } \\
\text { pelo Usaid (United States } \\
\text { Agency for International } \\
\text { Development). }\end{array}$ & $\begin{array}{l}\text { Baseada na satisfação dos } \\
\text { usuários, na disponibilidade } \\
\text { de profissionais do sexo } \\
\text { feminino (importante } \\
\text { devido fatores culturais) e } \\
\text { disponibilidade de medi- } \\
\text { camentos essenciais nas } \\
\text { unidades de saúde. }\end{array}$ & $\begin{array}{l}\text { Foco na } \\
\text { APS, mas } \\
\text { com- } \\
\text { preende } \\
\text { serviços } \\
\text { de todos } \\
\text { os níveis } \\
\text { de aten- } \\
\text { ção. }\end{array}$ \\
\hline
\end{tabular}

\section{Ashton et al., 200415. Nova Zelândia - Estudo de caso}

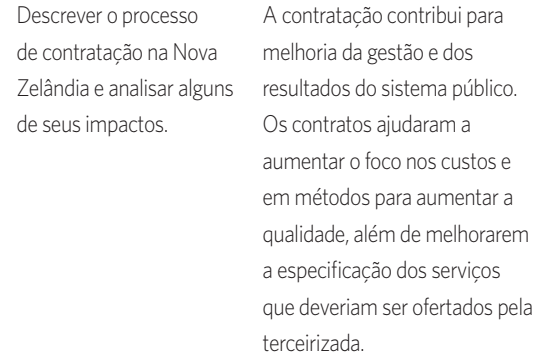

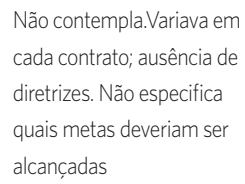

Não contempla.Variava em cada contrato; ausência de diretrizes. Não especifica quais metas deveriam ser alcançadas

\section{Não contempla.não avaliou 1. entre Regional Health} se houve o cumprimento Authorities RHA e Crown em cada contrato

Health Enterprises CHE (privadas). 2. Entre Health Funding Authority HFA e Hospital and Health services HHS (organizações sem fins lucrativos)
A maioria dos contratos incorporou alguma avaliação de qualidade. De maneira geral, incluíam categorias relacionadas a acesso, eficácia, eficiência e segurança. Também não havia diretrizes para avaliação da qualidade posta nos contratos.

\section{Charlesworth, 200126. Reino Unido - Estudo de caso}

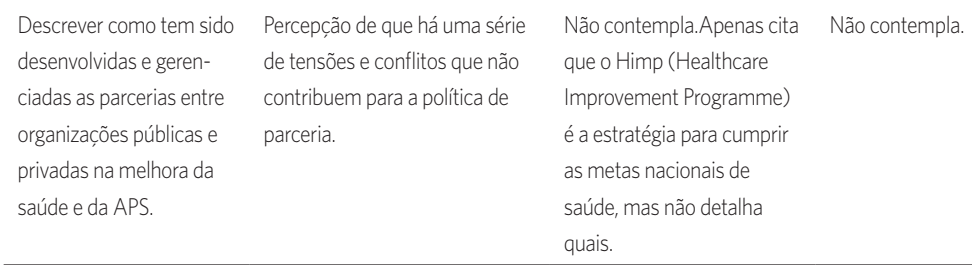

Não contempla.Apenas cita que o Himp (Healthcare Improvement Programme) é a estratégia para cumprir as metas nacionais de saúde, mas não detalha quais.

contribuem para a política de parceria.

Não contempla.

Nacontem .

Diferentes níveis

\section{Feldman, 199827. EUA - Ensaio descritivo}

Contracting out (similar Não contempla. APS à OS)

\begin{tabular}{|c|c|c|c|c|}
\hline $\begin{array}{l}\text { Estabelecem padrões de } \\
\text { desempenho com relação }\end{array}$ & $\begin{array}{l}\text { O não cumprimento das } \\
\text { metas estabelecidas exige }\end{array}$ & $\begin{array}{l}\text { Carve-out contract. Entre } \\
\mathrm{MBHCO}=\text { Managed }\end{array}$ & Não contempla. & $\begin{array}{l}\text { Secun- } \\
\text { dária }\end{array}$ \\
\hline ao tempo de resposta por & devolução de parte da taxa & Behavioral Health Carve & & \\
\hline contato telefônico, previsão & paga pelos contratantes. & Out e o contratante público & & \\
\hline e pontualidade do paga- & & ou privado. & & \\
\hline mento aos provedores dos & & & & \\
\hline serviços de saúde, custo & & & & \\
\hline projetado dos sinistros, & & & & \\
\hline metas de utilização, acesso & & & & \\
\hline aos serviços, satisfação dos & & & & \\
\hline suários, entre outros. & & & & \\
\hline
\end{tabular}
Compara como os cuidados em saúde mental eram fornecidos e discute o surgimento e as características de um novo modelo de oferta desses cuidados. Não contempla.Não apresenta resultados por não se tratar de

\author{
Estabelecem padrões de \\ contato telefônico, previsão \\ serviços de saúde, custo \\ projetado dos sinistros, \\ aos servicos, satisfacão dos
}


Quadro 2. (cont.)

\begin{tabular}{|c|c|c|c|c|c|c|}
\hline \multirow[b]{2}{*}{ Objetivo } & \multirow[b]{2}{*}{ Principais Resultados } & \multicolumn{2}{|c|}{ Metas e seus Cumprimentos } & \multirow{2}{*}{$\begin{array}{l}\text { Tipo de } \\
\text { Contratualização }\end{array}$} & \multirow[b]{2}{*}{ Ideia de Qualidade } & \multirow{2}{*}{$\begin{array}{l}\text { Nível de } \\
\text { atenção }\end{array}$} \\
\hline & & Metas & Cumprimentos & & & \\
\hline \multicolumn{7}{|c|}{ Halverson et al., 199728. EUA - Ensaio descritivo } \\
\hline $\begin{array}{l}\text { Descrever diferentes } \\
\text { modelos de privatização. }\end{array}$ & $\begin{array}{l}\text { Não contempla.Não apresenta } \\
\text { resultados por não se tratar de } \\
\text { um estudo empírico }\end{array}$ & $\begin{array}{l}\text { Cita que os contatos devem } \\
\text { garantir qualidade, acessibi- } \\
\text { lidade e custo dos serviços } \\
\text { providos pela privatização. }\end{array}$ & $\begin{array}{l}\text { Cita que o acompanha- } \\
\text { mento da performance } \\
\text { dos fornecedores privados } \\
\text { precisa ser realizado através } \\
\text { de } 5 \text { dimensões: indicado- } \\
\text { res de saúde, quantidade de } \\
\text { serviços prestados, custo, } \\
\text { acesso e satisfação do } \\
\text { consumidor. }\end{array}$ & Diferentes tipos. & Não contempla.. & $\begin{array}{l}\text { Não es- } \\
\text { pecifica }\end{array}$ \\
\hline \multicolumn{7}{|c|}{ McPake and Hongoro, 199529. Zimbábue - Estudo de caso } \\
\hline $\begin{array}{l}\text { Avaliar o sucesso ou não } \\
\text { da contratação entre } \\
\text { instituições públicas } \\
\text { e privadas do setor da } \\
\text { saúde, comparando com } \\
\text { um hospital da adminis- } \\
\text { tracão direta. }\end{array}$ & $\begin{array}{l}\text { O parceiro privado oferta } \\
\text { serviços com maior qualidade } \\
\text { e menor custo unitário. No } \\
\text { entanto, o contrato apresenta } \\
\text { falha em não conter o seu custo } \\
\text { total e por atender à minoria da } \\
\text { populacão. }\end{array}$ & $\begin{array}{l}\text { Não contempla.Não } \\
\text { existem metas claras } \\
\text { estabelecidas. }\end{array}$ & $\begin{array}{l}\text { Não contempla.Não há } \\
\text { monitoramento formal da } \\
\text { qualidade do serviço ou da } \\
\text { operação do contrato. }\end{array}$ & $\begin{array}{l}\text { Contracting out (similar } \\
\text { à OS) }\end{array}$ & Não contempla.. & $\begin{array}{l}\text { Atenção } \\
\text { terciária }\end{array}$ \\
\hline
\end{tabular}

Grupo C - Estudos que respondem diretamente ao objeto de pesquisa

Heard et al., 201330. Bangladesh - Estudo de caso

Avaliar a expansão da APS em Bangladesh comparando áreas administradas por uma ONG e pelo governo local.

\begin{abstract}
Houve melhora nas áreas administradas tanto pela ONG quanto pelo setor público, mas alguns indicadores foram maiores na área administrada pela ONG. Limitações metodológicas podem ter influenciado os resultados.
\end{abstract}

Contrato inclui 9 indicadores: porcentagens de cobertura vacinal infantil, cobertura de vitamina $\mathrm{A}$, tratamento para insuficiência respiratória aguda, tratamento para diarreia, de mães capazes de citar espontaneamente 3 métodos anticoncepcionais modernos, cobertura de cuidados pré-natais, taxa de prevalência de contraceptivos, cobertura vacinal contra tétano, partos com assistência especializada

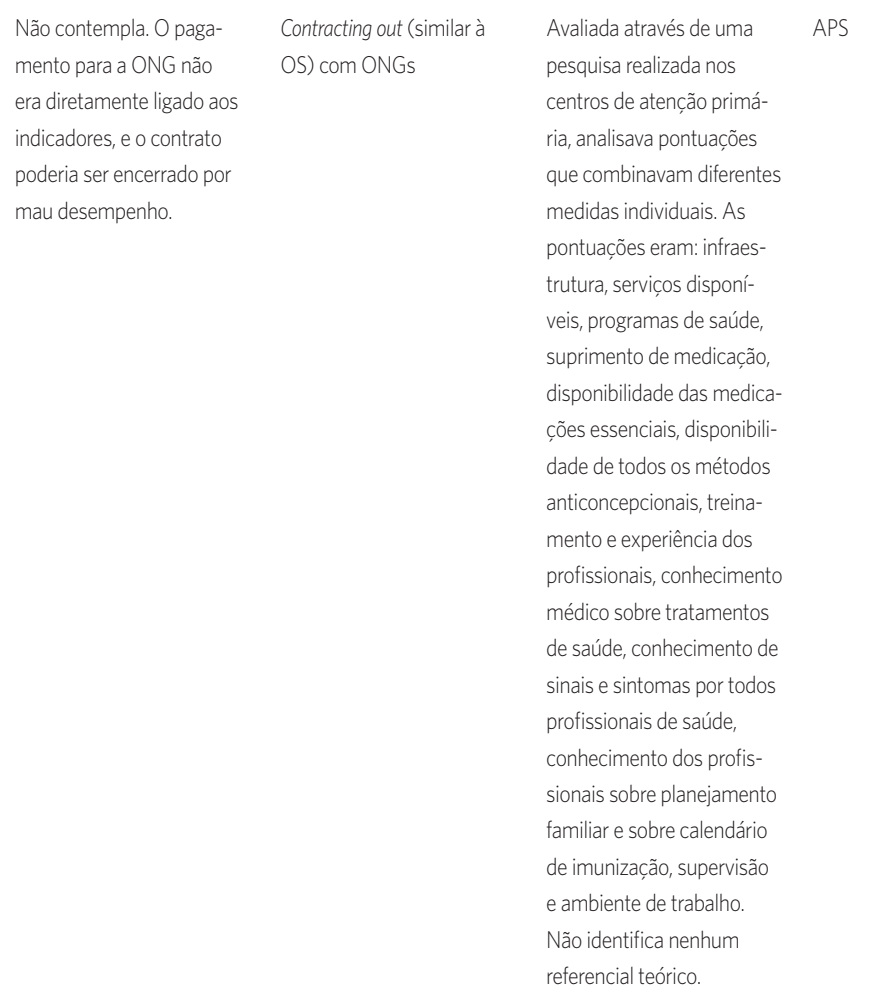


Quadro 2. (cont.)

\begin{tabular}{|c|c|c|c|c|c|c|}
\hline \multirow[b]{2}{*}{ Objetivo } & \multirow[b]{2}{*}{ Principais Resultados } & \multicolumn{2}{|c|}{ Metas e seus Cumprimentos } & \multirow{2}{*}{$\begin{array}{l}\text { Tipo de } \\
\text { Contratualização }\end{array}$} & \multirow[b]{2}{*}{ Ideia de Qualidade } & \multirow{2}{*}{$\begin{array}{l}\text { Nível de } \\
\text { atenção }\end{array}$} \\
\hline & & Metas & Cumprimentos & & & \\
\hline \multicolumn{7}{|c|}{ Jacobs et al., 201031. Camboja - Estudo de caso } \\
\hline $\begin{array}{l}\text { Descrever e analisar a } \\
\text { transição dos serviços de } \\
\text { saúde administrados por } \\
\text { ONGs para administra- } \\
\text { ção governamental. }\end{array}$ & $\begin{array}{l}\text { Foi possível a transição da } \\
\text { administração da ONG para } \\
\text { o governo com melhora dos } \\
\text { indicadores traçados para ava- } \\
\text { liação. Isso foi facilitado através } \\
\text { da gestão de desempenho e a } \\
\text { vinculação desse com a remu- } \\
\text { neração de profissionais, além } \\
\text { de incentivos nos programas } \\
\text { verticais de saúde, envolvendo } \\
\text { todos os atores da saúde. }\end{array}$ & $\begin{array}{l}\text { Consultas, consulta de pré- } \\
\text {-natal, partos nas unidades } \\
\text { de saúde, uso de contracep- } \\
\text { tivo e imunização. }\end{array}$ & $\begin{array}{l}\text { Não contempla.Cita que os } \\
\text { contratos possuíam indica- } \\
\text { dores e recompensas finan- } \\
\text { ceiras por seus alcances, } \\
\text { formas de monitoramento, } \\
\text { prazos e nível de aceitação } \\
\text { de desempenho. }\end{array}$ & $\begin{array}{l}\text { Modelo híbrido entre con- } \\
\text { tracting out (similar à OS) e } \\
\text { contracting in. Transição da } \\
\text { administração pela ONG } \\
\text { para um sistema operado } \\
\text { pelo governo. }\end{array}$ & $\begin{array}{l}\text { Associa melhor desempe- } \\
\text { nho com a remuneração } \\
\text { dos profissionais e cita pre- } \\
\text { ocupação com a qualidade } \\
\text { do cuidado prestado. Não } \\
\text { relaciona com o cumpri- } \\
\text { mento de metas. }\end{array}$ & $\begin{array}{l}\text { Todos os } \\
\text { níveis de } \\
\text { atenção. } \\
\text { Foco na } \\
\text { APS }\end{array}$ \\
\hline
\end{tabular}

\section{Soeters e Griffiths, 2003². Camboja - Estudo de caso}

Descrever a experiência no Camboja em um dos distritos submetidos ao contracting in

\section{As famílias passaram a gastar} menos com saúde com outros provedores e aumentaram a procura pelos serviços públicos de saúde. O modelo contracting-in foi mais eficiente que a administração governamental, porém, o contracting-out foi superior à todos. Pagar os profissionais de saúde por desempenho se mostrou a melhor opção.
Detalha a forma de incentivo financeiro e pagamento dos profissionais de saúde. Continha metas financeiras e metas como cobertura de EPI, número de pacientes com tuberculose internados, porcentagem de diagnóstico e tratamento corretos
Não contempla.Não havia um sistema adequado de monitoramento dos indicadores não financeiros.
Foco no contracting in com ONG. Compara com o contracting out e com reference districts (operavam sob a estrutura de gestão governamental padrão e serviam como grupo controle para comparação).

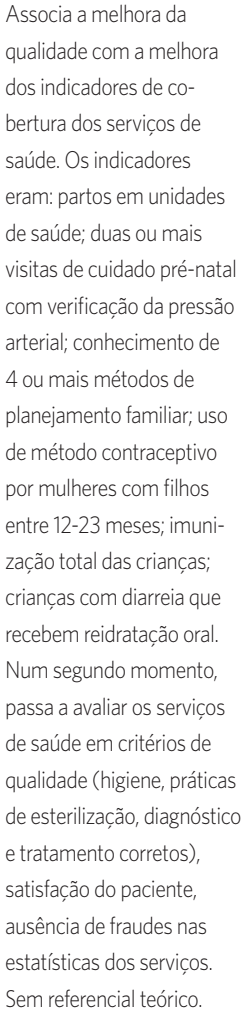

\section{Abramson, 200133. Costa Rica - Estudo de caso}

Analisar a experiência da Não há dados suficientes para Costa Rica em monitorar e avaliar os contratos entre uma cooperativa e o ministério da saúde na atenção primária à saúde. falar do aumento da qualidade porque eles avaliaram apenas como 'sim' ou 'não'. A avaliação do desempenho do contratado não estava ligada aos resultados além dos relacionados à utilização dos serviços.
Definidas em 3 categorias: organização, qualidade e prestação direta de serviços. Cada um com indicadores específicos para análise.
Estipula que os resultados gerais de uma avaliação de 6 meses inferior a $90 \%$ do acordo teriam um impacto direto e proporcional de até $2,5 \%$ sobre o orçamento disponível para os 6 meses seguintes. cooperativa COOPESALUD Mensurada em termos de APS Contracting out (similar oportunidade, continuidade, adequação, acessibilidade e satisfação do usuário. Avaliada apenas com 'sim' ou 'não'. As avaliações aplicadas não forneciam dados úteis sobre melhoria da qualidade do cuidado e da eficiência. 
Uma segunda análise foi realizada, e as informações obtidas com os artigos presentes no terceiro grupo deram origem ao quadro 3, que aprofunda a análise sobre metas e seus cumprimentos nos contratos, especificando os indicadores contidos nas metas quantitativas e qualitativas, a existência de multas ou de bonificações de acordo com o desempenho apresentado e o impacto proporcionado na qualidade em saúde.

Nenhum desses estudos citou a presença de metas qualitativas nos contratos, e dois ${ }^{30,33}$ não apresentaram multas ou punições previstas caso as metas não fossem atingidas.

Quadro 3. Síntese dos artigos incluídos com foco no fenômeno: aspectos de cumprimento do contrato, tipos de metas do contrato e relação entre cumprimento e qualidade da atenção à saúde. 2020

\begin{tabular}{|c|c|c|c|c|c|}
\hline \multicolumn{3}{|c|}{ Aspectos do Cumprimento do Contrato } & \multicolumn{2}{|l|}{ Metas do Contrato } & \multirow{2}{*}{$\begin{array}{l}\text { Cumprimento da } \\
\text { meta impacta na } \\
\text { qualidade? }\end{array}$} \\
\hline $\begin{array}{l}\text { Apresenta estudo } \\
\text { de linha-base? }\end{array}$ & Multas e punições & Bonificação & Quantitativas & Qualitativas & \\
\hline \multicolumn{6}{|c|}{ Heard et al., 201330. Bangladesh } \\
\hline $\begin{array}{l}\text { Apresenta linha- } \\
\text {-base. }\end{array}$ & $\begin{array}{l}\text { O contrato pode- } \\
\text { ria ser finalizado } \\
\text { por mau desem- } \\
\text { penho. }\end{array}$ & $\begin{array}{l}\text { Bônus calculado atra- } \\
\text { vés de uma fórmula } \\
\text { (não descrita) usando } \\
\text { taxas de cobertura dos } \\
\text { serviços de saúde. }\end{array}$ & $\begin{array}{l}\text { Porcentagens de cobertura vacinal } \\
\text { infantil, cobertura de vitamina A, tra- } \\
\text { tamento para insuficiência respiratória } \\
\text { aguda, tratamento para diarreia, de } \\
\text { mães capazes de citar espontaneamen- } \\
\text { te } 3 \text { métodos anticoncepcionais moder- } \\
\text { nos, cobertura de cuidados pré-natais, } \\
\text { taxa de prevalência de contraceptivos, } \\
\text { cobertura vacinal contra tétano, partos } \\
\text { com assistência especializada. }\end{array}$ & Não apresenta. & $\begin{array}{l}\text { Não estabelece } \\
\text { nenhuma relação } \\
\text { de impacto, já que } \\
\text { os indicadores ava- } \\
\text { liados para mensu- } \\
\text { ração da qualidade } \\
\text { eram distintos dos } \\
\text { estabelecidos como } \\
\text { meta no contrato } \\
\text { de gestão. }\end{array}$ \\
\hline
\end{tabular}

Jacobs et al., 201031. Camboja

Apresenta com- Sem especificaparação do de- ções. sempenho entre diferentes anos do contrato.

\section{Soeters, Griffiths, 2003². Camboja}

Apresenta linha- Sem especifica-base. ções.
Recompensa financeira paga ao DHTAT - District Health Technical Advisory Team de acordo com o desempenho das unidades de saúde.
$35 \%$ de consultas de cuidados curativos para população mais pobre, $50 \%$ de consultas de cuidados pré-natais, $20 \%$ de partos em serviços de saúde, 40\% de uso de anticoncepcionais por mulheres casadas e $75 \%$ de cobertura vacinal em criancas.
Contrato com os trabalhadores da saúde: pagamento básico mensal 55\%, 15\% de bônus pela pontualidade e 30\% de bônus pelo desempenho. Num segundo momento, há a criação de subcontratos com os gestores das unidades de saúde, que poderiam decidir sobre o pagamento do bônus aos profissionais.
Metas financeiras mensais para o departamento ou a unidade de saúde, além de metas como cobertura de EPI, número de pacientes com tuberculose internados, porcentagem de diagnóstico e tratamento corretos. Metas dos subcontratos: $3 x$ maiores do que o nível de produção existente para consultas ambulatoriais, atendimento ambulatorial per capita, total de atendimento pré-natal, oferta de contraceptivos, partos em serviços de saúde, receitas financeiras provenientes de taxas de saúde pagas pelos usuários.

\section{Não apresenta. Não estabelece nenhuma relação de impacto, já que os indicadores ava- liados para mensu- ração da qualidade eram distintos dos estabelecidos como meta no contrato de gestão.}


Quadro 3. (cont.)

\begin{tabular}{|c|c|c|c|c|c|}
\hline \multicolumn{3}{|c|}{ Aspectos do Cumprimento do Contrato } & \multicolumn{2}{|l|}{ Metas do Contrato } & \multirow{2}{*}{$\begin{array}{l}\text { Cumprimento da } \\
\text { meta impacta na } \\
\text { qualidade? }\end{array}$} \\
\hline $\begin{array}{l}\text { Apresenta estudo } \\
\text { de linha-base? }\end{array}$ & Multas e punições & Bonificação & Quantitativas & Qualitativas & \\
\hline \multicolumn{6}{|c|}{ Abramson, 200133. Costa Rica } \\
\hline Sem linha-base. & $\begin{array}{l}\text { Estipula que os } \\
\text { resultados gerais } \\
\text { de uma avaliação } \\
\text { de } 6 \text { meses infe- } \\
\text { riores a } 90 \% \text { do } \\
\text { acordo teriam um } \\
\text { impacto direto e } \\
\text { proporcional de } \\
\text { até } 2,5 \% \text { sobre o } \\
\text { orçamento dis- } \\
\text { ponível para os } 6 \\
\text { meses seguintes. }\end{array}$ & Sem especificações. & $\begin{array}{l}\text { Definidas em } 3 \text { categorias com indi- } \\
\text { cadores específicos: organização (\% } \\
\text { de encaminhamentos e conformidade } \\
\text { entre o fornecimento de custo biomé- } \\
\text { dico e informações de orçamento em } \\
\text { tempo hábil); qualidade (existência de } \\
\text { comissão para analisar mortes maternas } \\
\text { e infantis e estabelecer planos de inter- } \\
\text { venção, aplicação de protocolos, análise } \\
\text { de tempo de espera, análise de opera- } \\
\text { ções eficientes do serviço de farmácia, } \\
\text { existência de sistema de sugestão e } \\
\text { satisfação do usuário, aplicação de } \\
\text { instrumento de satisfação do usuário); e } \\
\text { prestação direta de serviços (cobertura } \\
\text { de acompanhamento do desenvolvi- } \\
\text { mento infantil de } 0-1 \text { ano e de 1-6 anos, } \\
\text { cobertura vacinal, aconselhamento para } \\
\text { adolescentes sobre saúde reprodutiva, } \\
\text { para mulheres acima de } 20 \text { anos e pla- } \\
\text { nejamento familiar; análise qualitativa e } \\
\text { quantitativa de problemas ginecológicos } \\
\text { e obstétricos). }\end{array}$ & Não apresenta. & $\begin{array}{l}\text { Não estabelece } \\
\text { nenhuma relação } \\
\text { de impacto. }\end{array}$ \\
\hline
\end{tabular}

\section{Discussão}

\section{Aspectos metodológicos}

Os artigos foram divididos de acordo com sua semelhança metodológica em cinco grupos. O primeiro grupo diz respeito aos estudos de caso ${ }^{\mathbf{1 2}, 14-18,20,23,26,29,30-33}$, sendo composto por mais da metade dos artigos que fazem parte desta revisão. Em que pese o fato de os estudos de caso serem muito usados nesses tipos de estudo de caráter mais administrativo, existem críticas a essa metodologia relativas à sua capacidade de generalização e à subjetividade de mensuração e confiabilidade dos dados extraídos. Porém, o estudo de caso pode ser considerado um método que permite estudos mais aprofundados e específicos de situações mais complexas ${ }^{34}$, possibilitando uma análise do fenômeno estudado sem dissociá-lo de seu contexto. Isso se mostra relevante para o objeto de estudo desta revisão integrativa, uma vez que para entender o funcionamento e as características dos diferentes contratos de gestão é preciso considerar o sistema de saúde no qual eles estão inseridos.

O segundo grupo é formado por 3 estudos qualitativos ${ }^{16,22,24}$. Esse tipo de metodologia tem um caráter interpretativo dos temas estudados, e os fenômenos são investigados e interpretados segundo o significado atribuído pelos participantes da pesquisa ${ }^{35}$. Isso se mostrou importante nesse caso, pois, de forma geral, os artigos discorreram sobre as PPP e a visão dos sujeitos envolvidos na sua implantação, 
que são essenciais na compreensão e crítica dessas modalidades de gestão ${ }^{4}$.

Composto por 3 artigos, o terceiro grupo engloba os ensaios descritivos ${ }^{19,27,28}$, que descrevem os diferentes modelos de privatização e evidenciam seus potenciais riscos e benefícios, exemplificando a experiência em diversos países. Esse tipo de método refere-se à obtenção de informações sobre um fenômeno e à descrição de suas características, sem o compromisso com a explicação desse fenômeno ${ }^{36}$. Por isso, os conteúdos apresentados pelos ensaios têm uma validade científica baixa, e são, portanto, questionáveis quanto aos seus achados e/ou argumentos.

O quarto grupo é composto por 2 revisões sistemáticas ${ }^{17,21}$, sendo que uma delas também incorpora um estudo de caso ${ }^{17}$ e analisa o papel das organizações sem fins lucrativos nos sistemas de saúde em comparação com as organizações lucrativas, enquanto a outra revisão analisa o impacto do comissionamento nos serviços de saúde ${ }^{21}$. Como as revisões sistemáticas integram informações de um conjunto de estudos, proporcionando um resumo das evidências existentes e possibilitando agregar maiores resultados relevantes ${ }^{37}$, a inclusão desses dois artigos permitiu agregar maior consistência dos achados sobre as contratualizações na tentativa de generalização para outros países com perfil semelhante.

Por fim, o quinto grupo é também formado por dois estudos do tipo transversal ${ }^{13,25}$, que apresentam a vantagem de serem de baixo custo e servirem para examinar em uma amostra a presença ou ausência de efeitos após exposição a uma causa ${ }^{38}$ no mesmo período. No caso desta revisão, os artigos incluídos com essa metodologia investigaram a qualidade em saúde, um comparando o serviço de agências com e sem fins lucrativos ${ }^{13}$, e outro comparando a qualidade com os custos empregados ${ }^{25}$.

Esses dados sobre os tipos metodológicos são importantes para refletir sobre como o tema pode ser sensível à metodologia empregada. Ao verificar que a maior parte dos artigos usa o estudo de caso, é possível que haja maior vinculação do alcance dos resultados projetados sobre o suposto impacto nos indicadores de saúde, contrariando, em tese, aquilo que a literatura sobre o tema reitera ${ }^{4}$. Entretanto, é essencial ter em mente que os achados desses estudos, em sua maioria, são muito contexto-dependentes, e, portanto, a importação mecânica de seus achados para outros contextos incorre, necessariamente, em falácias.

\section{Metas e seus cumprimentos nos contratos de gestão}

Comparou-se se informações sobre metas dos contratos de gestão estão presentes ou ausentes e se há informações sobre seus cumprimentos. Apenas 6 artigos citaram claramente a existência de metas e as descreveram 20,27,30,31-33. Desses, apenas 2 relatam os cumprimentos das metas estabelecidas ${ }^{27,33}$, enquanto outros 5 artigos apresentavam a importância de monitorar e avaliar os resultados e o desempenho esperados e estabelecidos nos contratos de

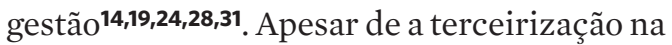
saúde ser pautada pelos contratos de gestão ${ }^{\mathbf{1 , 4}}$, chama atenção que pouco se fale sobre metas e resultados esperados.

Esse fato não deve impressionar de modo algum, afinal, há uma clara inversão entre a medida de quantidade de trabalho com o produto produzido, conforme os estudos críticos sobre o tema vêm denunciando ${ }^{6,7}$. Não se trata de medir a quantidade de trabalho que remunere um produto produzido, mas de medir a quantidade de produto produzido para remunerar o trabalho feito ${ }^{\mathbf{4 2}}$. É nessa díade que a questão da qualidade desaparece, e que, quando existe, não é delimitada conforme os estudos sobre o tema assim o exigem $^{9,10}$. Nesse interim, o cumprimento da meta tampouco importa, já que parece ser um pressuposto sabido de antemão que não há (ou não deve haver) relação entre o cumprimento da meta com a qualidade. É aqui que vê-se nitidamente que o alcance das metas, para o contratado, deve se desvincular do impacto 
sobre os indicadores de saúde da população, dessa vez, reforçando o que a literatura sobre o tema versa, conforme discutido por Barbosa e Elias 4 .

\section{Tipos de contratualização}

Neste tema, avaliaram-se os tipos de contratualização que são mencionados nos artigos. As PPP possuem cinco características: formadas por no mínimo dois agentes econômicos, o setor público e o setor privado; os dois lados da parceria apresentam papéis distintos e possuem o direito de negociar os termos da parceria; permitem contratos de longo prazo; uma das partes pode compartilhar seus valores fundamentais, como símbolos ou bens materiais; os riscos e as responsabilidades são compartilhados entre os setores públicos e privados ${ }^{16}$. Nesse conceito amplo de PPP, existem diferentes modelos.

O modelo contracting in refere-se à relação entre dois operadores do setor público, promovendo uma gestão privada dentro da configuração do setor público, sendo citado em dois estudos sobre a saúde no Camboja ${ }^{\mathbf{3 1}, \mathbf{3 2}}$. Esse modelo se assemelha aos conceitos de economia planificada e competição administrada managed competition ${ }^{32}$. Sua possível vantagem estaria em garantir uma gestão alinhada com as políticas em saúde e necessidades da população, já que a tomada de decisões pelo gestor ocorre em colaboração com as autoridades públicas de saúde.

Já no modelo contracting out, todo controle sobre a equipe de profissionais e o orçamento diz respeito à contratada, garantindo-lhe autonomia. Nesse caso, a atuação fica vinculada ao contrato de gestão ${ }^{32}$. No Brasil, esse modelo equivale ao adotado pelas OS. Com o funcionamento de forma semelhante, o modelo de comissionamento também é pautado por um contrato e envolve as áreas de planejamento estratégico, contratação de serviços - no caso serviços de saúde - e monitoramento e avaliação desses serviços ${ }^{21}$. O modelo clinical commissioning group, presente no Reino
Unido ${ }^{24}$, diferencia-se do comissionamento pelo fato de ser comandado por um grupo de médicos de família e não mais por uma terceirizada. Dos 22 estudos incluídos nesta revisão, 12 deles abordam esse tipo de contratação (contracting out) $\mathbf{1 2 , 1 7 , 1 8 , 2 0 , 2 4 - 2 6 , 2 8 , 2 9 , 3 0 , 3 2 , 3 3}$ ou apenas definem a contratualização como PPP19,22. Esse achado possivelmente é justificado pelo relato frequente de que os indicadores em saúde, muitas vezes avaliados nos estudos, apresentavam melhora em relação ao modelo público usado anteriormente nos diversos países que aderiram às PPP, daí o grande número de experiências com esse tipo de contratualização. Apesar de poder apresentar benefícios, existem resultados negativos associados à contratualização, como não apresentar melhorias na qualidade dos serviços de saúde e proporcionar irrisória integração com programas nacionais de saúde 20 .

Existe, ainda, o modelo Build-rent-transfer, específico da Turquia, onde o Estado aloca um terreno para que a iniciativa privada construa um hospital e receba o direito de obter créditos através desse equipamento, ou seja, o setor privado realiza a construção num terreno público e depois aluga a edificação para o Estado, que fica responsável pela manutenção e por reparos na estrutura. Com o término do prazo de empréstimo ao setor privado, a edificação é transferida ao Estado ${ }^{16}$.

Com relação ao modelo carved out, citado em um dos artigos ${ }^{27}$, trata-se de uma forma em que a gestão e o risco financeiro de um seguro-saúde geral são separados de serviços de saúde mental/comportamental.

Por fim, o modelo de agenciamento é exposto no sistema de saúde da Costa Rica ${ }^{23} \mathrm{e}$ nele é cedido um pequeno controle do governo aos hospitais e clínicas através de um contrato, proporcionando descentralização do sistema.

\section{Ideia de qualidade}

Dos artigos incluídos nesta revisão, 9 não definiam nenhumaideia com relação à qualidade 16-19,22,26-29. Entre os que explicitavam a análise da qualidade 
dos serviços de saúde, a maioria limitava-se a se basear em métricas e indicadores. Um artigo ${ }^{\mathbf{1 4}}$ enumera os princípios de um sistema de saúde de qualidade - centrado no paciente, seguro, eficaz, acessível, eficiente e equitativo -, enquanto outro $\operatorname{artigo}^{13}$ define qualidade dos cuidados em saúde como "um equilíbrio ideal entre as possibilidades realizadas e uma estrutura de normas e valores"13. Apenas um artigo ${ }^{12}$ evidenciava um referencial teórico conceituando sua definição de qualidade baseada na avaliação proposta por Donabedian, que considera as dimensões: estrutura, processos e resultados ${ }^{\mathbf{1 2}}$. Outro artigo ${ }^{\mathbf{2 4}}$ expôs os padrões de qualidade a partir das diretrizes do National Institute for Health and Care Excelllence - Nice (Reino Unido), que também são baseadas no conceito de Donabedian ${ }^{39}$.

Fica o questionamento de como pode ser possível afirmar que a contratualização favorece o aumento da qualidade dos serviços prestados se os estudos não aprofundam o debate sobre esse tema e não se utilizam sequer de um referencial teórico 9 . É interessante notar que o fato de os estudos relacionarem-se com a qualidade do ponto de vista retórico, não apresentam processos de verificação da qualidade em função do tipo de cumprimento contratual. Isso chama atenção para a limitação dos estudos que, por vezes, afirmam que o cumprimento das metas garante mais qualidade aos usuários atendidos.

\section{Aspectos do cumprimento do contrato de gestão}

Entre os artigos que compõem esta revisão, 4 estão incluídos no grupo que responde diretamente ao objeto desta pesquisa ${ }^{30-33}$, que é analisar se existe relação entre o cumprimento de metas quantitativas dos contratos de gestão e a qualidade da atenção à saúde. Desses artigos, apenas um ${ }^{33}$ não apresenta linha-base que permita comparação do desempenho dos contratos. Com relação à especificação quanto à existência de multas e punições, os estudos que descrevem as experiências de Bangladesh ${ }^{\mathbf{3 0}}$ e Costa Rica ${ }^{33}$ são os que apresentam multa por mau desempenho ou redução orçamentária caso as metas estipuladas no contrato não sejam atingidas. Gridley ${ }^{24}$ questiona se as necessidades de saúde seriam atendidas caso não houvesse metas e incentivos, já que não seriam vistas como prioridades.

Analisando as bonificações citadas nos contratos, apenas um artigo ${ }^{33}$ não cita esse item, e seu autor pondera que não ir além da meta declarada no contrato caracterizaria uso ineficiente de recursos e que uma recompensa motivaria a superar as metas estabelecidas. Os outros 3 artigos discorrem sobre recompensas de acordo com o desempenho apresentado ${ }^{31}$, bônus de acordo com a taxa de cobertura alcançada pelos serviços de saúde ${ }^{30}$ e pagamento de bônus aos profissionais também a partir de seus desempenhos ${ }^{32}$.

\section{Metas do contrato de gestão}

Nenhum dos artigos que respondem ao objeto de pesquisa ${ }^{30-33}$ apresenta metas qualitativas. Abransom ${ }^{33}$ cita em seu estudo que alguns provedores consideraram que os indicadores de qualidade presentes nos contratos nem sempre eram capazes de expressar a qualidade dos serviços de saúde. Diante dessa afirmação, dificilmente se consegue comprovar que a contratualização realmente proporciona melhora da qualidade em saúde. Se os indicadores não expressam a qualidade dos serviços, por que basear os contratos apenas em metas quantitativas?

No que diz respeito às metas quantitativas, todos os estudos ${ }^{30-33}$ abordavam a cobertura dos serviços, ações e procedimentos em saúde. Apenas um artigo ${ }^{33}$ definia indicadores específicos para avaliar organização, qualidade e prestação direta de serviços.

\section{Relação entre cumprimento das metas e qualidade}

Neste tema, tentar-se-á estabelecer relação entre o cumprimento de metas e a qualidade, incluindo a qualidade da atenção à saúde. 
Field ${ }^{20}$ argumenta em seu artigo que é limitada a evidência de que modelos de PPP melhorem a prestação de serviços de saúde, dada a dificuldade em avaliar programas complexos de prestação de serviços em oposição à avaliação de intervenções únicas ou pacotes de intervenções ${ }^{20}$. Na mesma linha de argumentação, alguns provedores da Nova Zelândia consideravam que as avaliações da qualidade focavam principalmente em processos e não nos resultados obtidos nos serviços de saúde ${ }^{15}$.

Ballaroti et al. ${ }^{40}$ concluem em seu estudo que a comparação do desempenho dos serviços no alcance de metas não seria suficiente para determinar qual serviço cumpre melhor seu papel na rede de saúde, pois o modelo de contratualizações pautado na avaliação de desempenho teria o potencial de gerar distorções e levar os serviços de saúde a direções distintas das planejadas ${ }^{\mathbf{4 0}}$. Portanto, artigos comumente publicados no Brasil comparando o desempenho de serviços sob gestão pública e privada, como o exemplo do estudo de Souza e Scatena ${ }^{12}$, presente nesta revisão, poderiam gerar conclusões distorcidas, não proporcionando informações suficientes para afirmar qual serviço cumpre melhor seu papel. Além disso, qualquer objetivo no campo da saúde precisa de avanços coordenados em outras áreas para ser alcançado, principalmente no setor social, sendo possível apenas com gerência intergovernamental ${ }^{41}$, e não apenas com base no desempenho de serviços isolados.

Nesse ponto, é importante lembrar a diferença entre 'desempenho' e 'resultados', frequentemente tomados como sinônimos na literatura corrente. O desempenho está associado aos resultados de um serviço, mas certamente não se deve confundir com este último. O desempenho é uma defasagem com relação a uma métrica estabelecida, cujo resultado do serviço se demonstra geralmente aquém ou (raramente) além do esperado. Assim sendo, o desempenho é uma diferença relacionada a uma métrica elaborada arbitrariamente, costumeiramente a serviço dos interesses do empregador ${ }^{6}$. O resultado, no entanto, é algo muito mais polissêmico. Cabe aqui apenas ressaltar que, no âmbito da mensuração da qualidade na gestão dos serviços de saúde, resultados, 'donabedianamente' falando, são 'processos', e, raramente, os verdadeiros resultados dos serviços de saúde (as medidas dos índices epidemiológicos) são considerados como resultados ${ }^{\mathbf{4 2}, 43}$. Pelo contrário, os procedimentos se tornam os resultados dos serviços e, portanto, o objeto da aferição.

Isso se relaciona bem com o controle (de resultados) imposto pelas formas de contratualização. Tal mecanismo representa uma nova forma de controle e que vem acompanhada do estabelecimento de sanções positivas e negativas. A especificidade do resultado como produto máximo dessa filosofia de gestão deposita nas metas a redução do escopo administrativo, sendo estas representativas de toda cadeia de intangíveis intrínseca aos processos organizacionais, das quais a qualidade é uma delas ${ }^{6}$.

Nesse diapasão, as metas dos processos organizacionais não servem necessariamente para alcançar os verdadeiros resultados dos serviços de saúde, como citado anteriormente. Isso faz com que o atendimento das necessidades em saúde da população passe a ser negligenciado. Considerando a taxonomia proposta por Cecílio ${ }^{44(119)}$, atender ao conjunto das necessidades em saúde relacionadas à criação de vínculos afetivos entre o usuário e a equipe e/ou profissional - o que, em suas palavras, "significa o estabelecimento de uma relação contínua no tempo, pessoal e intransferível, calorosa: encontro de subjetividades" - estaria prejudicado, bem como o conjunto ligado à autonomia, que diz respeito à capacidade de reconstrução dos próprios sentidos de vida e no modo de viver de cada pessoa, o que é possível através da educação em saúde, por exemplo ${ }^{44}$, e que, em termos de metas desses contratos, passa a não ter muita significância pelo fato de não ser um 'procedimento' passível de mensuração objetiva. Com profissionais cobrados por desempenho, o estabelecimento de vínculo com os usuários e as propostas de 
educação em saúde são prejudicados por não serem vistos como prioridade. Afinal, esses profissionais são cobrados para atingir as metas impostas pela contratualização com foco na oferta que os serviços podem proporcionar do ponto de vista contábil, enquanto as necessidades em saúde não são mensuráveis nesse nível de 'cálculo racional' para os contratos.

Um ponto importante a ser ressaltado é a escassez de estudos sobre o cenário das contratualizações no Brasil e a avaliação da qualidade, dificultando a análise desse fenômeno no Sistema Único de Saúde (SUS), visto que é relevante considerar o sistema de saúde no qual a contratualização está inserida, e extrapolar os achados de outros países dissociaria o fenômeno de seu contexto. Sendo assim, torna-se inapropriado discutir sobre a contrarreforma e associá-la com o desempenho das OS no SUS, uma vez que nesta revisão não se encontraram estudos suficientes sobre a realidade brasileira que proporcionassem subsídios para um debate mais aprofundado. Contudo, uma afirmação é possível de ser feita: que o cumprimento de metas na saúde, como expressão material associada à contrarreforma do Estado, no bojo da dissolução do Estado Social Capitalista ${ }^{2}$, é um fenômeno de alcance mundial, conforme visto na diversidade de países incluídos que usam essas formas de contratação.

Com todos os elementos apresentados, comprova-se que não existem evidências científicas suficientes que confirmem que a contratualização aumenta a qualidade dos serviços de saúde. Especialmente pelo fato de que as qualidades metodológicas da maioria dos estudos revisados encontram-se em nível 4 (evidências de estudos descritivos - não experimentais - ou com abordagem qualitativa) ${ }^{45}$. Sendo o objeto de estudo desta revisão a descoberta se o cumprimento das metas dos contratos de gestão estabelece alguma relação com a atenção à saúde, é importante conceituá-la. Segundo o dicionário da educação profissional em saúde ${ }^{46}$, atenção à saúde pode ser definida como:
Atenção à saúde designa a organização estratégica do sistema e das práticas de saúde em resposta às necessidades da população. É expressa em políticas, programas e serviços de saúde consoante os princípios e as diretrizes que estruturam o Sistema Único de Saúde (SUS)46(39).

Ora, por ser a atenção à saúde algo amplo, que engloba, além dos campos da assistência, onde estão contidos os serviços de saúde, o campo das intervenções ambientais e das políticas externas ao setor saúde, fica evidente a dificuldade em relacionar mudanças de qualidade na atenção à saúde com as metas dos contratos de gestão. Ademais, vê-se que os estudos se limitam a estudar os modelos de contratualização de forma restrita aos serviços de saúde e que, ainda assim, nem demonstram relação com qualidade da assistência direta propriamente dita.

Dada a escassez de estudos realizados no Brasil que abordam os contratos de gestão de forma ampla, questiona-se se tal fato possa ser explicado pelo empenho de grandes grupos em limitar essas pautas e dificultar o acesso à informação. Com o desempenho das OS resumidos à gradação de resultados de produtividade e deixando de funcionar como ferramenta gerencial para qualificar o serviço, conforme apontado por Carnut e Narvai ${ }^{6}$, apreende-se, também, que os contratos de gestão perdem seu sentido de controle. Nos últimos anos, tornaram-se públicas denúncias de irregularidades nos contratos celebrados com diferentes Organizações Sociais da Saúde por todo o País ${ }^{47,48}$. No estado de São Paulo, por exemplo, em 2018, foi instaurada uma Comissão Parlamentar de Inquérito (CPI) que identificou supostos atos de improbidade administrativa e evidenciou a falta de controle do Estado sobre as OS, principalmente sobre os subcontratos firmados por essas instituições e outros prestadores de serviços ${ }^{\mathbf{4 8 , 4 9}}$.

O grande volume de recursos financeiros empregado nessas parcerias com OS dão a dimensão da importância de fiscalizar e de, 
no mínimo, rever como os contratos de gestão se estabelecem. No período entre 2013 e 2018, as OS do estado de São Paulo receberam mais de $\mathrm{R} \$ 50$ bilhões ${ }^{47}$, e, no Rio de Janeiro, entre 2019 e 2020, $\mathrm{R} \$ 1,8$ bilhão ( $56 \%$ das despesas da Secretaria Estadual de Saúde) foi repassado às OS citadas em denúncia realizada pelo Ministério Público Federal48. Um dos fatores, levantados pela CPI em São Paulo, que dificulta a auditoria sobre esses recursos é que os gastos com as OS são diluídos no orçamento da Secretaria de Saúde ${ }^{50}$.

\section{Limitações desta revisão}

Através do método de revisão sistemática integrativa, este artigo procurou sintetizar o conhecimento existente sobre o objeto de pesquisa e realizar inferências e interrelação dos resultados de forma crítica. Devido à limitação do método em focar no objeto pesquisado, muitos estudos foram identificados na busca inicial, e apenas poucos estudos foram elegíveis, além da maioria dos artigos incluídos apenas tangenciar ou responder parcialmente ao questionamento aqui proposto.

Outra limitação é relacionada à falta de estudos encontrados sobre o objeto de pesquisa no contexto brasileiro, sendo o interesse inicial da pesquisa abordar a contratualização no SUS.

\section{Implicações para políticas públicas}

O artigo confirmou não ser possível relacionar o cumprimento de metas com qualidade da atenção/assistência à saúde, sendo improcedente, segundo os dados desta revisão, admitir que os modelos de PPP, semelhantes às Organizações Sociais em Saúde no Brasil, e o estabelecimento de metas contratuais traz benefícios e gera aumento na qualidade dos serviços de saúde. Sendo assim, gestores públicos podem rever o processo de terceirização e a transferência da execução de atividades no campo saúde, que poderiam voltar a ser desenvolvidas exclusivamente pelo Estado, ou, ao menos, seria indicado que os gestores revissem a forma como os contratos de gestão são estabelecidos, a natureza de suas metas e como estas são pactuadas, executadas e, ainda, monitoradas. Os gestores públicos poderiam fomentar e incentivar a realização de mais pesquisas que avaliem a qualidade de forma ampla, fundamentada teoricamente, considerando a saúde num contexto amplo e não se limitando à assistência apenas.

Outra possibilidade seria estabelecer metas de acordo com o perfil epidemiológico da região compreendida no contrato de gestão e em consonância com melhoria dos indicadores de saúde.

\section{Avanços desta revisão e agenda de pesquisa}

Identificou-se que os estudos não avaliam a qualidade levando em consideração um referencial teórico e se limitam a avaliá-la apenas no que diz respeito à assistência à saúde, ainda que as metas estipuladas não se relacionassem com os indicadores escolhidos para análise, e não de forma mais ampla, englobando a atenção à saúde.

O conhecimento sobre essa temática pode avançar com pesquisas que avaliem a qualidade dentro do fenômeno da contratualização no SUS.

\section{Conclusões}

Apesar da existência de estudos que abordem a transferência da administração de serviços de saúde para a iniciativa privada e de relatos de experiência que citam os contratos de gestão, a literatura científica mostra que pouco se discute sobre a qualidade. A falta da utilização de um referencial teórico nos artigos, no caso desta pesquisa, sendo citado o proposto por Donabedian, mostra a dificuldade da avaliação ampliada da qualidade e a limita a atingir indicadores preestabelecidos, além de distorcer o significado de 'resultados' em saúde.

Dos 22 estudos incluídos nesta revisão sistemática integrativa, apenas 4 respondem 
diretamente ao questionamento realizado, e fica evidenciado que nesses estudos as metas propostas nos contratos não se relacionam com os indicadores que avaliam a qualidade, além de não existirem metas qualitativas nas contratualizações estudadas. Diante dos estudos revisados nas bases de dados trabalhadas, não é possível estabelecer relação entre metas dos contratos de gestão e qualidade da atenção à saúde, visto que os estudos se restringem à assistência à saúde.

Outro achado é a insuficiência de estudos realizados no Brasil, mostrando a necessidade de se estudar esse tema no SUS e ampliar a avaliação de qualidade no contexto da atenção à saúde.

\section{Colaboradores}

Melo MV (0000-0001-8017-4403)*, Carnut L (0000-0001-6415-6977)* e Mendes Á (00000002-5632-4333)*contribuíram igualmente para a elaboração do manuscrito quanto a concepção, planejamento, análise e interpretação, revisão crítica do conteúdo e aprovação da versão final.

\section{Referências}

1. Ibanez N, Vecina Neto G. Modelos de gestão e o SUS. Ciênc. Saúde Colet. 2007; 12(supl):1831-1840.

2. Boschetti I. Assistência social e trabalho no capitalismo. São Paulo: Cortez; 2016.

3. Hobsbawn E. Era dos extremos. São Paulo: Companhia das Letras; 1995.

4. Barbosa NB, Elias PEM. As organizações sociais de saúde como forma de gestão público/privado. Ciênc. Saúde Colet. 2010; 15(5):2483-2495.

5. Garrido-Pinzon J, Bernardo MH. Vivências de trabalhadores da saúde em face da lógica neoliberal: um estudo da atenção básica na Colômbia e no Brasil. Cad. Saúde Pública. 2017; 33(9):e00050716.

6. Carnut L, Narvai PC. Avaliação de desempenho de sistemas de saúde e gerencialismo na gestão pública brasileira. Saúde Soc. 2016; 25(2):290-305.

7. Mendes A, Carnut L. Capitalismo contemporâneo em crise e sua forma política: o subfinanciamento e o gerencialismo na saúde pública brasileira. Saúde soc. 2018; 27(4):1105-1119.

8. Bonato VL. Gestão de qualidade em saúde: melhorando assistência ao cliente. Mundo Saúde. 2011; 35(3):319-331.

9. Adami NP. Melhoria da qualidade nos serviços de enfermagem. Acta Paul Enf. 2000; (13):190-196.

10. Silva LMV, Formigli VLA. Avaliação em saúde: limites e perspectivas. Cad. Saúde Pública. 1994;10(1):8091. and Contributor ID). 
11. Soares CB, Hoga LAK, Peduzzi M, et al. Revisão integrativa: conceitos e métodos utilizados na enfermagem. Rev. Esc. Enferm. USP. 2014; 48(2):335-45.

12. Souza PC, Scatena JHG. Avaliação da qualidade da assistência hospitalar do mix público-privado do sistema único de saúde no estado de Mato grosso: um estudo multicaso. Rev. adm. Saúde. 2013; 15(59):7988.21 .

13. Haldiman KL, Tzeng HM. A comparison of quality measures between for-profit and nonprofit medicare-certified home health agencies in Michigan. Home Health Care Serv Q. 2010; 29(2):75-90.

14. O'Brien S, Edge N, Clark S. A strategy to reposition the South Australian health system for quality and value. Aust. J. Primary Health, 2015. (22):26-33.

15. Ashton T, Cumming J, McLean J. Contracting for health services in a public health system: the New Zealand experience. Health Policy. 2004; 69(1):21-31.

16. Top M, Sungur C. Opinions and evaluations of stakeholders in the implementation of the public-private partnership (PPP) model in integrated health campuses (city hospitals) in Turkey. Int J Health Plann Manage. 2019; 34(1):e241-e263.

17. Almeida AS. The role of private non-profit healthcare organizations in NHS systems: Implications for the Portuguese hospital devolution program. Health Policy. 2017; 121(6):699-707.

18. Heard A, Awasthi MK, Ali J, et al. Predicting performance in contracting of basic health care to NGOs: experience from large-scale contracting in Uttar Pradesh, India. Health Policy Plan. 2011; 26(supl1):i13-9.

19. Sekhri N, Feachem R, Ni A. Public-private integrated partnerships demonstrate the potential to improve health care access, quality, and efficiency. Health Aff (Millwood). 2011; 30(8):1498-507.

20. Field E, Abo D, Samiak L, et al. A Partnership Model for Improving Service Delivery in Remote Papua
New Guinea: A Mixed Methods Evaluation. Inter. J. Health Policy Manag. 2018; 7(10):923-933.

21. Gardner K, Davies GP, Edwards K, et al. A rapid review of the impact of commissioning on service use, quality, outcomes and value for money: implications for Australian policy. Aust. J. Primary Health. 2016; (22):40-49.

22. Barbosa AP, Malik AM. Desafios na organização de parcerias público-privadas em saúde no Brasil. Análise de projetos estruturados entre janeiro de 2010 e março de 2014. Rev. Adm. Pública. 2015; 49(5):11431165.

23. Lee T, McKee D. An Empirical Evaluation of Devolving Administrative Control to Costa Rican Hospital and Clinic Directors. Inter. J. Health Serv. 2015; 45(2):378-397.

24. Gridley K, Spiers G, Aspinal F, et al. Can General Practitioner Commissioning Deliver Equity and Excellence? Evidence from Two Studies of Service Improvement in the English NHS. Journal of Health Services Res. Policy. 2012; 17(2):87-93.

25. Ameli O, Newbrander W. Contracting for health services: effects of utilization and quality on the costs of the Basic Package of Health Services in Afghanistan. Bull World Health Organ. 2008; 86(12):920-8.

26. Charlesworth J. Negotiating and managing partnership in primary care. Health Soc Care Community. 2001; 9(5):279-85.

27. Feldman S. Behavioral health services: carved out and managed. Am J Manag Care. 1998; 4(supl):59-67.

28. Halverson PK, Kaluzny AD, Mays GP, et al. Privatizing health services: alternative models and emerging issues for public health and quality management. Qual Manag Health Care. 1997; 5(2):1-18.

29. McPake B, Hongoro C. Contracting out of clinical services in Zimbabwe. Soc Sci Med. 1995; 41(1):13-24. 
30. Heard A, Nath DK, Loevinsohn B. Contracting urban primary healthcare services in Bangladesh - effect on use, efficiency, equity and quality of care. Trop Med Int Health. 2013; (18):861-870.

31. Jacobs B, Thomé JM, Overtoom R, et al. From public to private and back again: sustaining a high service-delivery level during transition of management authority: a Cambodia case study. Health Policy Plan. 2010; 25(3):197-208.

32. Soeters R, Griffiths F. Improving government health services through contract management: a case from Cambodia. Health Policy Plan. 2003; 18(1):74-83.

33. Abramson WB. Monitoring and evaluation of contracts for health service delivery in Costa Rica. Health Policy Plan. 2001; 16(4):404-11.

34. Senger I, Paço-Cunha E, Senger CM. O estudo de caso como estratégia metodológica de pesquisas científicas em administração: um roteiro para o estudo metodológico. Rev Adm. 2004; 3(4).

35. Campos CJG, Siqueira C. Investigação qualitativa perspectiva geral e importância para as ciências da nutrição. Acta Port. Nutri. 2018; (14):30-34.

36. Leal EJM. Produção acadêmico-científica [recurso eletrônico]: a pesquisa e o en-saio. Cadernos de ensino. Formação continuada. Ensino Superior. Ano 7, n. 9. Itajaí, 2011.

37. Sampaio RF, Mancini MC. Estudos de revisão sistemática: um guia para síntese criteriosa da evidência científica. Rev. bras. fisioter. 2007; 11(1):83-89.

38. Hochman B, Nahas FX, Oliveira Filho RS, et al. Desenhos de pesquisa. Acta Cir. Bras. 2005; 20(supl2):2-9.

39. NICE - National Institute for Health and Care Excellence. [acesso em 2020 dez 19]. Disponível em: https://www.nice.org.uk/standards-and-indicators/ how-to-use-quality-standards\#measure.

40. Ballarotti B, Corneau FG, Junqueira V, et al. Reflexões de médicos sobre o trabalho na Estratégia de
Saúde da Família sob a gestão das Organizações Sociais. Interface (Botucatu). 2019; (23):e180082.

41. Kliksberg B. A modernização do Estado para o desenvolvimento social: algumas questões-chave. Rev Adm. Púb. 1996; 30(1):78-90.

42. Carnut L, Mendes Á. Capital-Estado na crise contemporânea: o gerencialismo na saúde pública. Argum. 2018; 10(2):108-121.

43. Carnut L, Masseran JAM. Entre a filosofia jurídica e a saúde coletiva: o conceito de desempenho no Decreto $\mathrm{n}^{0} 7.508 / 2011$ vis-à-vis a integralidade da assistência à luz do pós-positivismo. R. Dir. sanit. 2017; 18(1):37-56.

44. Cecílio LCO. As necessidades de saúde como conceito estruturante na luta pela integralidade e equidade na atenção em saúde. In: Pinheiro R, Mattos RA organizadores. Os sentidos da integralidade na atenção e no cuidado à saúde. Rio de Janeiro: UERJ, IMS: ABRASCO; 2006. p. 117-130.

45. Souza MT, Silva MD, Carvalho R. Revisão integrativa: o que é e como fazer. Einstein. 2010; 8(1Pt1):1026.

46. Pereira IB, França Lima JC. Dicionário da educação profissional em saúde. 2. ed. Rev. Ampl. Rio de Janeiro: EPSJV; 2008.

47. São Paulo. CPI OSS - Relatório Final. Suplemento Diário Oficial do Estado de São Paulo. 2018 [acesso em 2021 fev 6]; 128(175). Disponível em: https://www. al.sp.gov.br/repositorio/arquivoWeb/com/com5772. pdf.

48. Galdo R. Fraudes na saúde: levantamento aponta que OSs citadas em documentos do MPF receberam quase $\mathrm{R} \$ 2$ bi do estado. Extra. 2020 set 6. [acesso em 2021 fev 6]. Disponível em: https://extra.globo.com/noticias/saude-e-ciencia/fraudes-na-saude-levantamento-aponta-que-oss-citadas-em-documentos-do-mpf-receberam-quase-2-bi-do-estado-rvl-1-24626384. html. 
49. Macedo F. Entidades não se sentem obrigadas a prestar contas, diz presidente da CPI das OSS. Estadão. 2019 jun 4. [acesso em 2021 fev 6]. Disponível em: https://politica.estadao.com.br/blogs/fausto-macedo/ entidades-nao-se-sentem-obrigadas-a-prestar-contas-diz-presidente-da-cpi-das-oss/.

50. Machado L. CPI das OSS aprova relatório após retirar denúncias contra governador de SP e secretário adjunto. G1. 2018 set 12. [acesso em 2021 fev 6].
Disponível em: https://gl.globo.com/sp/sao-paulo/ noticia/2018/09/12/cpi-das-oss-aprova-relatorio-apos-retirar-denuncias-contra-governador-de-sp-e-secretario.ghtml.

Recebido em 26/02/2021

Aprovado em 05/10/2021

Conflito de interesses: inexistente

Suporte financeiro: não houve 